\section{Extraterrestrial hydrogeology}

\author{
Victor R. Baker · James M. Dohm • Alberto G. Fairén • \\ Ty P. A. Ferré - Justin C. Ferris · Hideaki Miyamoto • \\ Dirk Schulze-Makuch
}

\begin{abstract}
Subsurface water processes are common for planetary bodies in the solar system and are highly probable for exoplanets (planets outside the solar system). For many solar system objects, the subsurface water exists as ice. For Earth and Mars, subsurface saturated zones have occurred throughout their planetary histories. Earth is mostly clement with the recharge of most groundwater reservoirs from ample precipitation during transient iceand hot-house conditions, as recorded through the geologic and fossilized records. On the other hand, Mars is mostly in an ice-house stage, which is interrupted by endogenic-driven activity. This activity catastrophically drives short-lived hydrological cycling and associated climatic perturbations. Regional aquifers in the Martian highlands that developed during past, more Earth-like
\end{abstract}

Received: 25 June 2004 / Accepted: 23 December 2004

Published online: 26 February 2005

(C) Springer-Verlag 2005

V. R. Baker $(\bullet) \cdot$ J. M. Dohm · T. P. A. Ferré Department of Hydrology and Water Resources, University of Arizona,

Tucson, AZ, 85721, USA

e-mail: baker@hwr.arizona.edu

V. R. Baker · H. Miyamoto

Lunar and Planetary Laboratory,

University of Arizona,

Tucson, AZ, USA

A. G. Fairén

Centro de Biología Molecular,

Universidad Autónoma de Madrid,

28049, Cantoblanco, Madrid, Spain

J. C. Ferris

Water Resources Research Center,

University of Arizona,

Tucson, AZ, 85721, USA

H. Miyamoto

Department of Geosystem Engineering,

University of Tokyo,

Tokyo, Japan

D. Schulze-Makuch

Department of Geology,

Washington State University,

Pullman, WA, 99164, USA conditions delivered water to the northern plains. Water was also cycled to the South Polar Region during changes in climate induced by endogenic activity and/or by changes in Mars' orbital parameters. Venus very likely had a warm hydrosphere for hundreds of millions of years, before the development of its current extremely hot atmosphere and surface. Subsequently, Venus lost its hydrosphere as solar luminosity increased and a run-away moist greenhouse took effect. Subsurface oceans of water or ammonia-water composition, induced by tidal forces and radiogenic heating, probably occur on the larger satellites Europa, Ganymede, Callisto, Titan, and Triton. Tidal forces operating between some of the small bodies of the outer solar system could also promote the fusion of ice and the stability of inner liquid-water oceans.

Résumé Les processus de subsurface impliquant l'eau sont communs pour les corps planétaires du système solaire et sont très probables sur les exoplanètes (planètes en dehors du système solaire). Pour plusieurs objets du systèmes solaire, l'eau de subsurface est présente sous forme de glace. Pour la Terre et Mars, les zones saturées de subsurface apparaissent à travers toute leur histoire planétaire. La Terre est particulièrement clémente avec la recharge des réservoirs, avec de amples précipitations, des conditions glaciaires et de fortes chaleurs, comme l'atteste les enregistrements géologiques et paléontologiques. D'un autre côté, Mars se trouve dans une phase essentiellement glaciaire, qui est interrompue par des activités contraintes par les phénomènes endogéniques. Cette activité conduit de manière catastrophique à des cycles hydrologiques et à des perturbations climatiques brutaux. Les aquifères régionaux dans les haute terres martiennes qui se sont formés dans des conditions similaires aux conditions terrestres, alimentent les plaines du Nord. L'eau a également été déplacée vers le Pôle Sud martien durant des changements marqués par une forte activité endogénique et une modification des paramètres de l'orbite de Mars. Venus possèdait vraisemblablement une hydrosphère chaude durant des millions d'année, avant le développement de son atmosphère et sa surface particulièrement chaude. Par après Venus a perdit son hydrosphère alors que la luminosité solaire augmentait et qu'une humidité liée à un effet de serre s'installait. Les océans de subsurface d'eau ou d'eau ammoniacale, induits par les forces de marée et le chauffage radiogénique, 
Fig. 1 (Right) View of the solar system. Courtesy of the U.S. National Aeronautics and Space Administration/Jet Propulsion Laboratory-California Institute of Technology; revised from http://photojournal.wr.usgs.gov/ (Left) Composite of images and airbrush shaded-relief maps of the larger bodies of the solar system. Courtesy of Rich Kozak and U.S. National Aeronautics and Space Administration

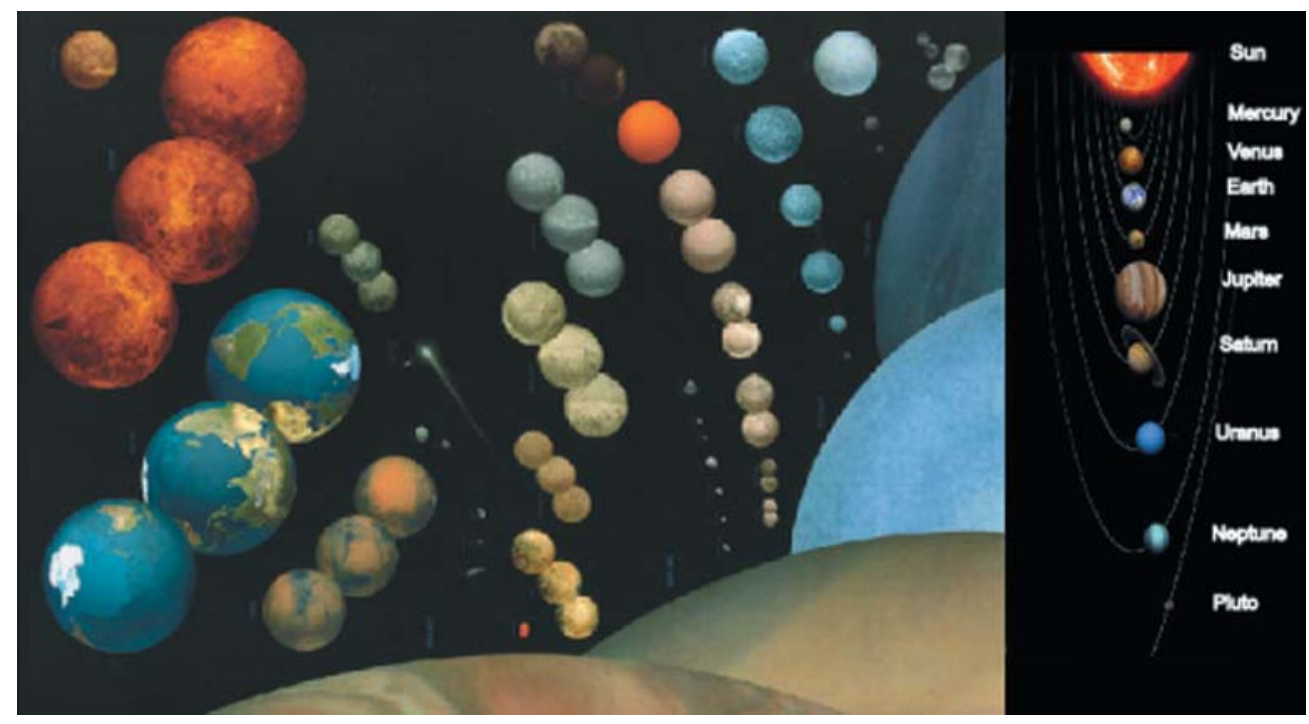

apparaissent probablement sur les satellites les plus importants (Europa, Ganymede, Callisto, Titan, Triton). Les forces de marée entre les petits corps externes du système solaire peuvent également occasionner la fusion de glace et la stabilité des océans internes d'eau liquide.

Resumen Los procesos hídricos subsuperficiales son comunes en cuerpos planetarios del sistema solar y son altamente probables para exoplanetas (planetas fuera del sistema solar). Para muchos cuerpos del sistema solar, el agua subsuperficial existe como hielo. Para la Tierra y Marte han ocurrido zonas saturadas subsuperficiales a través de sus historias planetarias. La Tierra es principalmente generosa con la recarga de la mayoría de reservorios de aguas subterráneas a partir de amplia precipitación reconocida en condiciones transitorias calientes y heladas, tal y como aparece en los registros fósiles y geológicos. Por otro lado, Marte se encuentra principalmente en una etapa de cámara de hielo la cual es interrumpida por actividad de tipo endogénico. Esta actividad pone en funcionamiento catastróficamente ciclos hidrológicos de vida corta y perturbaciones climáticas asociadas. Acuíferos regionales en las montañas de Marte que se desarrollaron en el pasado en condiciones similares a la Tierra distribuyen agua a las planicies del norte. El agua ha sido transportada hacia el sur de la región polar durante cambios en el clima inducidos por actividad endogénica y/o cambios en los parámetros orbitales de Marte. Venus muy probablemente tuvo una hidrósfera caliente durante cientos de millones de años, antes de que se desarrollara su atmósfera y superficie actual extremadamente caliente. Subsecuentemente, Venus perdió su hidrósfera a medida que la luminosidad solar aumentó y un efecto de invernadero húmedo escapatorio se llevó a cabo. Océanos subsuperficiales de composición agua o amoniaco-agua, inducidos por fuerzas de marea y calentamiento radiogénico, probablemente ocurren en los satélites más grandes como Europa, Ganimeda, Callisto, Titan y Triton. Las fuerzas de marea que operan entre los cuerpos pequeños del sistema solar externo podrían también promover la fusión de hielo y la estabilidad de líquido interno-aguas de los océanos.

Keywords Hydrogeology $\cdot$ Planets $\cdot$ Mars

\section{Introduction}

Recent space missions have revealed that Earth is not alone in having had, or is currently having, a hydrological cycle. Moreover, there are manifestations of surprisingly earth-like hydrological cycling on one planet: Mars. While near-surface indications of water movement are evident, subsurface hydrologic processes have not been directly imaged by many of the orbital sensors used in planetary exploration. Despite this lack of direct observation of subsurface hydrologic processes, the field of extraterrestrial hydrogeology is experiencing rapid growth. As this field begins to emerge from its infancy, it is appropriate to provide a brief review of the current concepts of the existence, both past and present, of water on and beneath the surface of extraterrestrial bodies. The nascent science of extraterrestrial hydrogeology will face many challenges in testing and expanding our concepts of subsurface water distributions on distant bodies. It is likely that in meeting these challenges, advances will be made in our understanding of the Solar System (Fig. 1) while honing our abilities to describe and predict hydrologic processes on Earth.

\section{Mars}

Present-day Mars has a mean atmospheric pressure at its surface of $600 \mathrm{~Pa}(6 \mathrm{mb})$. The atmosphere is composed of 95.3\% carbon dioxide, $2.7 \%$ nitrogen, and $1.6 \%$ argon. There are traces of other gases, notably water vapor. During the summer, water content in a vertical column of 


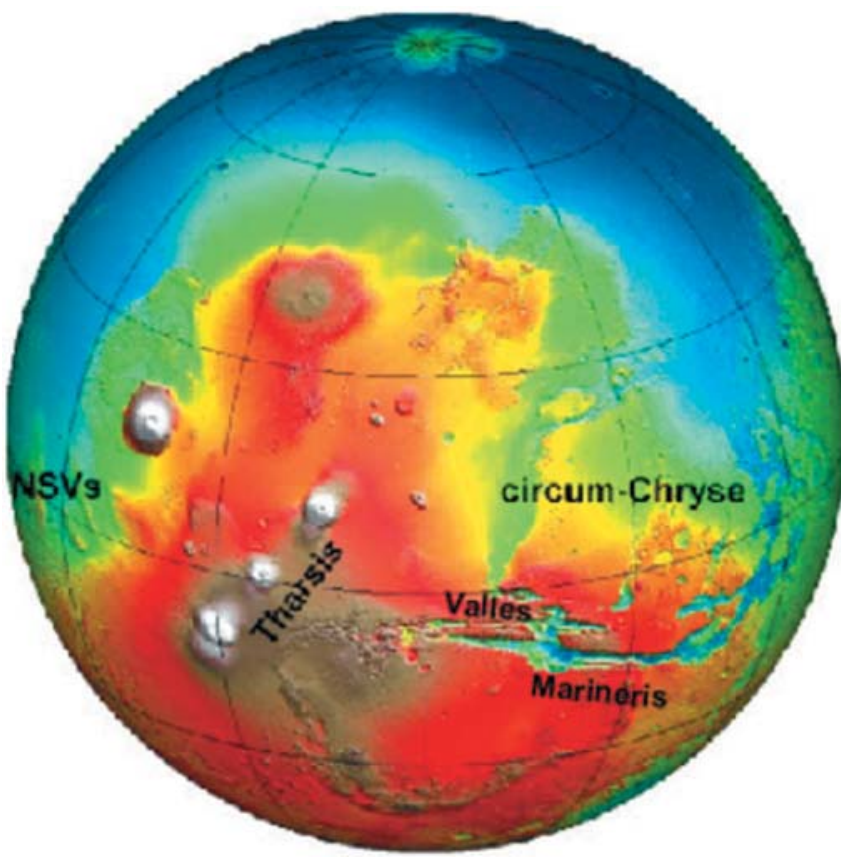

Fig. 2 Mars Orbiter Laser Altimeter map (MOLA) showing Tharsis and associated outflow channel systems, Circum-Chryse and northwestern slope valleys (NSVs), the northeast and northwest watersheds, respectively, and Valles Marineris, a canyon that would span the United Sates from roughly its western end to its eastern end. Courtesy of the MOLA Science Team

the atmosphere can reach 100 precipitable microns (pr $\mu \mathrm{m}$ ) over the water ice exposed at the north polar cap, but the surface average is about $20 \mathrm{pr} \mu \mathrm{m}$ (Smith 2002). Despite the incredibly low absolute value, about 1,000 times less than that of Earth, the very thin Martian atmosphere is nearly always close to saturation, and the tiny amounts of water regularly form clouds that strongly influence the energy balance at the planet's surface. Elemental information obtained through the gamma ray spectrometer (GRS) instrument onboard the Mars spacecraft Odyssey (Boynton et al. 2002; Feldman et al. 2002) supports the conclusion that there is a dynamic climate system operating on seasonal time scales with water vapor diffusing into and out of the surface. The efforts of the GRS Team have led to the recent discovery of large quantities of near-surface water ice, corroborating published geologic, geomorphic, and paleohydrologic information that had indicated a water-enriched planet sculpted by water/water-ice (Baker et al. 1991; Kargel and Strom 1992; Baker 1993; Parker et al. 1993; Scott et al. 1995; Dohm et al. 2001a) (e.g., Fig. 2).

Modern Mars is extremely cold. The planet is 1.5 times farther from the sun than Earth, and its current atmosphere affords little greenhouse warming. The mean surface temperature at the equator is about $-50^{\circ} \mathrm{C}$, but there is a huge range from about $-100^{\circ} \mathrm{C}$ at night to a peak of about $0^{\circ} \mathrm{C}$ in daytime. Polar latitudes are often much colder. Areas of stability for water ice under modern conditions in the Martian subsurface are estimated from generalized physical principles by Farmer and Doms

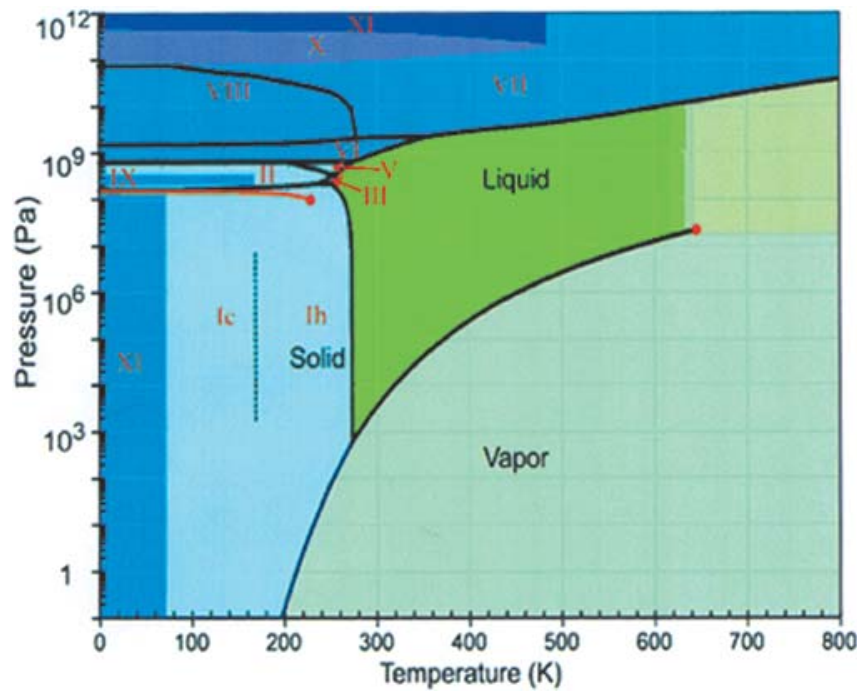

Fig. 3 Phase diagram for water. Stability fields for the solid, liquid, and gas phases as shown. All the different solid phases of ice involve hydrogen bonding of water molecules to four neighboring water molecules (from Chaplin 2003). Notice that the triple point is located very close to Earth's average temperature allowing all three phases to coexist under a wide variety of climatic conditions. Unique properties of water include: (1) very common compound in the universe with a molecular weight of $18.015 \mathrm{~g} / \mathrm{mol}$, (2) large range of liquidity $\left(0-100^{\circ} \mathrm{C}\right.$ at 1 bar) with a critical temperature of $375^{\circ} \mathrm{C}$ and a critical pressure of 215 bar extending the range of liquidity and temperatures at which organisms can survive in water, (3) highest density of water is at a temperature of $4^{\circ} \mathrm{C}$, which prevents bottom to top freezing of surface water bodies, (4) a good thermal insulator due to its high heat capacity (enthalpy of fusion $6.0 \mathrm{~kJ} /$ mol, enthalpy of vaporation $40.7 \mathrm{~kJ} / \mathrm{mol}$ ), (5) good insulator (dielectric constant: 80.1), (6) a good solvent for ionic and polar compounds, also formation of hydrogen bonds (dipole moment: $1.85 \mathrm{D}),(7)$ high surface water tension promoting surface chemistry, (8) a good shield for protecting organisms from UV radiation, and (9) a good environmental buffer as it dissociates into $\mathrm{H}^{+}$and $\mathrm{OH}^{-}$and allows for effective carbonate buffering (Schulze-Makuch and Irwin 2004)

(1979), Paige (1992), and Mellon and Jakosky (1995) (e.g., Fig. 3). Despite differences in detail, all these authors find zones at high latitudes where ice is stable throughout the year at depths within about a meter of the surface. Equatorial latitudes do not permit ice stability at depth because ice will tend to sublime and be lost to the atmosphere. However, these results apply only for long time scales, relatively rapid diffusion from buried ice to the atmosphere, and modern obliquity (about $25^{\circ}$ ). At higher obliquities, above about $32^{\circ}$, ice becomes stable everywhere at shallow depths (Mellon and Jakosky 1995).

Under present surface temperatures, all near-surface zones of Mars are perennially below $0^{\circ} \mathrm{C}$ below the upper meter or so of annual temperature change. That is, there is a planet-wide permafrost zone. Where water occurs in this zone it will constitute ground ice, comprising the Martian cryosphere. The thickness of the cryosphere is controlled at depth by the geothermal heat flux. Below some depth, subsurface temperatures rise above the melting point of water ice and ground water can occur as a liquid. The depth to this transition depends on the local geothermal 
gradient and the hydraulic conductivity of the cryosphere. For various presumed values of these parameters, Clifford (1993) estimated nominal cryosphere thicknesses of 2$5 \mathrm{~km}$ at equatorial latitudes, $3-6 \mathrm{~km}$ at mid latitudes, and $7-12 \mathrm{~km}$ at polar latitudes. Local occurrences of brines, hydrothermal activity, or gas hydrates may reduce these thickness estimates (Clifford and Parker 2001). The potential impacts of gas hydrate deposits are particularly interesting because of the possible trapping of $\mathrm{CO}_{2}, \mathrm{CH}_{4}$, or other gases in crystalline lattices of water (Kargel and Lunine 1998), which greatly lowers the thermal conductivity of ground ice. Although a thick ice-rich cryosphere has not been measured directly, its presence is inferred from a variety of geological indicators (Carr 1996; Baker 2001). MARSIS, a radar sounding instrument on the Mars Express spacecraft, will attempt to characterize the cryosphere and underlying unfrozen ground water.

\section{Subsurface water}

Until relatively recently, the prevailing view of the Martian crust employed a model of subsurface porosity that presumed an ubiquitous megaregolith produced by impact processes, overlain by relatively thin volcanic flows and other materials (Clifford 1993; Carr 1996). This model was developed by analogy to the Moon, where there is direct geological and geophysical evidence of a crust that was highly brecciated and fractured to depths of several kilometers because of the intensity of impacting processes during the early history of the solar system. The porosity of this megaregolith was presumed to decrease with depth by self compaction. However, recent discoveries show that layered deposits are exposed in the cratered highlands, such as in the Arabia Terra region, exhibiting exhumed impact craters, ancient channels, and fluvial and alluvial fans (Malin and Edgett 2000a). Collectively, these features indicate relatively high erosion rates during ancient periods on Mars (Baker et al. 2002). Paleotopographic reconstructions based on a synthesis of geologic information indicate that the layered materials may mark ancient basins and regional aquifer systems in the Tharsis and Arabia Terra regions that sourced large outflow channel systems (Dohm et al. 2001a, 2004). This brings into question the interpretation of ground water occurrence based on the presumed structure of the Martian crust. Recent discovery of spherical granules (referred to as blueberries) in the Meridiani Planum region of Mars revealed through the Mars exploration rover, Opportunity (Squyres et al. 2004), may represent fieldbased evidence of ground water activity (Chan et al. 2004). This region of Mars may have been the site of an extensive ancient ocean (covering approximately $1 / 3$ of the surface of the planet; see Fairén et al. 2003), possibly acidic (Fairén et al. 2004), which may have contributed to the formation of the spherical granules.

The current model of the Martian crust suggests that porosities and permeabilities may be highly variable. For example, lowland materials are interpreted to have been emplaced by both subaerial and subaqueous processes, which include eolian, volcanic, fluvial, mass-wasting, lacustrine, and marine processes of mainly Hesperian and Amazonian age (e.g., Scott and Tanaka 1986; Parker et al. 1993; Scott et al. 1995). On the other hand, the highland materials are interpreted to consist of mountain-building materials, such as the basement complex within the Thaumasia highlands and Coprates rise mountain ranges, as well as volcanic and intrusive materials and sedimentary deposits of possible eolian, fluvial, marine, glacial, and colluvial origin (e.g., Scott and Tanaka 1986; Tanaka 1986; Greeley and Guest 1987; Kargel et al. 1995; Dohm et al. 2001b; Williams et al. 2003). In addition, there was ancient, enhanced hydrogeologic activity related to magma/water-ice interactions among endogenic- and impact-induced basement fabrics in and surrounding the Tharsis and Elysium regions Mouginis-Mark (1985, 1990; Scott and Tanaka 1986; Greeley and Guest 1987; Dohm et al. 2001a, 2001b; Komatsu et al. 2004). These interactions were particularly important in the source regions of the Circum-Chryse outflow channel systems, where chaotic terrain and a diversity of collapse features are interpreted to mark large underground cavernous systems and stratified buried impact craters and associated fracture systems (Rodriguez et al. 2004a, 2004b). Application of current subsurface hydrologic analyses and methods of subsurface hydrologic characterization will play an important role in coupling geologic interpretations of the subsurface conditions and observations of hydrologically-controlled surface structures.

\section{Episodic hydrological change}

A genetic model (Baker et al. 1991) explains both longterm and short-term components of the ancient Mars hydrologic cycle. The episodic formation of Oceanus Borealis on the northern plains is one component of the short-term portion of this cycle. The hypothesis explains the phenomenally long epochs of post-heavy-bombardment time during which the Mars surface clearly had extremely cold and dry conditions, similar to those prevailing today. These long periods of quiescence and extremely slow surficial erosion were punctuated by shortduration $\left(\sim 10^{4}\right.$ to $10^{5}$ year) episodes of quasi-stable conditions, considerably wetter and somewhat warmer than those prevailing today at the planet's surface. Transition from a long-persistent cold-dry state is induced by magmatic-driven activity at Tharsis and to a lesser extent at Elysium, triggering cataclysmic outbursts of huge flood flows that carved the Martian outflow channels and ponded in the northern plains, forming water bodies ranging through time from oceans to lakes (Fairén et al. 2003).

The energy required to form the immense outflow channel floods was supplied by the thermotectonic effects of immense mantle plumes. Gas that accumulated beneath and in the ice-rich permafrost could have propelled the outbursts (Komatsu et al. 2000; Max and Clifford 2001). The release of radiatively active gases could have generated a transient greenhouse that coincided with the immense pondings of water that were produced by the outburst floods. The evidence for very recent outburst 
floods (Burr et al. 2002) suggests that a relatively small outburst episode occurred recently on Mars. Evidence for extensive sulfate salts on the Martian surface (Moore 2004 ) is also consistent with this model, in that the $\mathrm{SO}_{2}$ and water generated from the volcanism and flood outburst would have produced the acidic conditions to generate extensive sulfate salt emplacement on the Mars surface. The recent episode may also have been a trigger for water migration, leading to ice emplacement (Baker 2001) in latitudinal zonation for which orbital variations likely acted as the pacemaker (Head et al. 2003).

\section{Triggering of hydroclimatic change}

Episodic cold-dry/warmer-wet transitions can be ascribed to the cataclysmic outburst flooding of the outflow channels (Baker and Milton 1974; Baker 1982; Komatsu and Baker 1997). Peak outflow discharges of $10^{8}$ to $10^{9} \mathrm{~m}^{3} \mathrm{~s}^{-1}$ (Baker et al. 1991) collectively imply total released reservoir volumes of $10^{5}$ to $10^{7} \mathrm{~km}^{3}$ of water, using scaling relationships for terrestrial superfloods (Baker et al. 1992a). The higher volumes from these preliminary calculations match the volume of Oceanus Borealis estimated from inferred extent and MOLA topography (Head et al. 1999).

The immense peak discharges implied by the size and morphology of the outflow channels (Baker et al. 1992a) were not explained adequately by previous models. A mechanism whereby gas hydrate in the Martian permafrost zone is destabilized by episodes of very high heat flow (and associated volcanism), thereby releasing radiatively active gas from the lower permafrost zone (2$3 \mathrm{~km}$ depths), may help explain these enormous discharges. This process could involve carbon dioxide or methane (Kargel et al. 2000; Max and Clifford 2001). The dissolved gas from the underlying groundwater and the gas released from ice in the permafrost zone would contribute to explosively pressurized slurries of water and sediments in massive outbursts (Komatsu et al. 2000).

\section{Outflow channel processes}

The discharges of the outflow channels are key to determining the overall water balance that would be associated with the above scenario. Sediment-charged Martian floods from outflow channels (Baker 1982) would have entered the ponded water body on the northern plains as powerful turbidity currents. This is the reason for the lack of obvious delta-like depositional areas at the mouths of the outflow channels. High-velocity floods, combined with the effect of the reduced Martian gravity (lowering the settling velocities for entrained sediment) promote unusually coarse-grained washload (Komar 1980), permitting the turbidity currents to sweep over the entire northern plains. The latter are mantled by a vast deposit, the Vastitas Borealis formation, which covers almost $3 \times 10^{7} \mathrm{~km}^{2}$, or approximately one-sixth of the planet's area. This sediment is contemporaneous with the postNoachian outflow channels, and it was likely emplaced as the sediment-laden outflow channel discharges became hyperpycnal flows upon entering ponded water on the plains (Ivanov and Head 2001). In another scenario, Clifford and Parker (2001) envision a Noachian "ocean," contemporaneous with the highlands valley networks, and fed by a great fluvial system extending from the south polar cap, through Argyre and the Chryse Trough, to the northern plains.

The immense floods that initially fed Oceanus Borealis seem to have been the triggers for hydroclimatic change through the release of radiatively active gases, including $\mathrm{CO}_{2}$ and water vapor (Gulick 1998). During the shortduration thermal episodes of cataclysmic outflow, a temporary cool-wet climate prevailed. Water that evaporated off Oceanus Borealis was transferred to uplands, including the Tharsis volcanoes and portions of the southern highlands, where precipitation as snow promoted the growth of glaciers, and rain contributed to valley development and lakes. However, this cool-wet climate was inherently unstable. Water from the evaporating surface-water bodies was lost to storage (1) in the highland glaciers, and (2) as infiltration into the porous lithologies of the Martian surface. This latter effect, more than any lack of precipitation, is the likely cause of the limited upland dissection on Mars (Baker and Partridge 1986). However, recent high-resolution data show that previous notions of limited upland dissection (e.g., Carr 1996) were misinterpretations due to the lower resolution imagery available at the time.

Progressive loss of carbon dioxide from the quasistable atmospheres of outflow episodes was probably facilitated by dissolved gas in infiltrating acidic water. Also, silicate weathering producing bicarbonate may have been carried into the subsurface by infiltration. However, paleoenvironmental surface and near-surface conditions were most likely acidic, thus carbonate precipitation would not be expected to occur as a widespread global phenomena. This is also supported by the Mars orbiters and rovers, which have not detected any carbonate rocks. The developing permafrost from a cooling climate would have trapped this gas in the subsurface. The permafrost zone would have developed as the surface greenhouse effect, promoted by an outflow episode, went into decline because of the progressive loss of its gases to the subsurface by solution in infiltrating waters. As the permafrost extended downward into the stability field for $\mathrm{CO}_{2}$ clathrate, this gas hydrate would then accumulate above the gas-charged groundwater. Thus, the long-term reservoir for carbon on Mars is a sequestering underground in the forms of (1) clathrate (gas hydrate), (2) gascharged ground water, and (3) possible carbonate cements in crustal rocks. During the post-heavy bombardment time carbon was transferred to the atmosphere only occasionally and for relatively short durations as greenhouse-promoting carbon dioxide during the cataclysmic ocean-forming episodes. The volcanism and water vapor associated with outflow events generate an acidic atmosphere (water, sulfur dioxide, carbon dioxide) that promotes the formation of salt crusts over the entire surface. These ideas seem to explain the lack of observed carbonates in spectra from the Thermal Emission Spec- 
trometer instrument on Mars Global Surveyor (Fairén et al. 2004). The short duration of the post-Noachian oceanforming phases is also consistent with the very low degradation rates (Golombek and Bridges 2000) for the Martian surface during the long period after heavy bombardment.

The recent discovery of small amounts of methane in the Martian atmosphere (Kerr 2004) opens up an even more intriguing scenario for hypothesized outflow events. The methane could be derived from a deep biosphere of microbes using a methanogenic metabolic pathway in the Martian groundwater. Isolated below the ice-rich permafrost, this biosphere would produce the more effective greenhouse gas methane, which would be stored in the ground ice as gas hydrate. Release of methane by outflow episodes (one of which seems to have occurred in very recent geological time) would then have effectively helped to produce a more quasi-stable atmospheric warming in addition to that triggered by carbon dioxide itself.

\section{Hydrogeological implications of "young" Martian landforms}

Recent discoveries from MOC images show that Mars displays a diverse suite of exceptionally young, globally distributed water-related landforms. If observed on Earth, these landforms would all be well understood to have aqueous origins that occurred over relatively short time scales (100s to 1,000 s of years) in a much warmer, wetter, and denser atmosphere than occurs on Mars today (Baker 2001). These features were first demonstrated by MOC images from the MGS orbiter showing numerous small gullies generated by surface runoff on hillslopes (Malin and Edgett 2000b). The gullies are most likely formed by debris-flow processes and the melting of near-surface ground ice (Costard et al. 2002; Miyamoto et al. 2004a). Melting can be induced at the appropriate latitude by changes in the solar insolation that would be induced by the immense shifts in Martian obliquity that are retrodicted to have occurred during the past few million years (Head et al. 2003). The gullies are uncratered, and their associated debris-flow fan deposits are superimposed on both eolian bedforms (dunes or wind ripples) and on polygonally patterned ground, all of which cover extensive areas that are also uncratered (Malin and Edgett $2000 \mathrm{~b})$. The patterned ground is itself a very strong indicator of near-surface, ice-related processes in the active (seasonally thawed) layer above the Martian permafrost zone (Seibert and Kargel 2001).

Exceptionally young outflow channels and associated volcanism occur in both the Cerberus Plains and the Tharsis regions of Mars (Hartmann and Berman 2000; Mouginis-Mark 1990). Data from MGS show that localized water releases, interspersed with lava flows, occurred within the last 10 million years (Berman and Hartmann 2002; Burr et al. 2002). The huge discharges associated with these floods and the temporally related volcanism should have introduced considerable water into active hydrological circulation on Mars. It is tempting to hy-

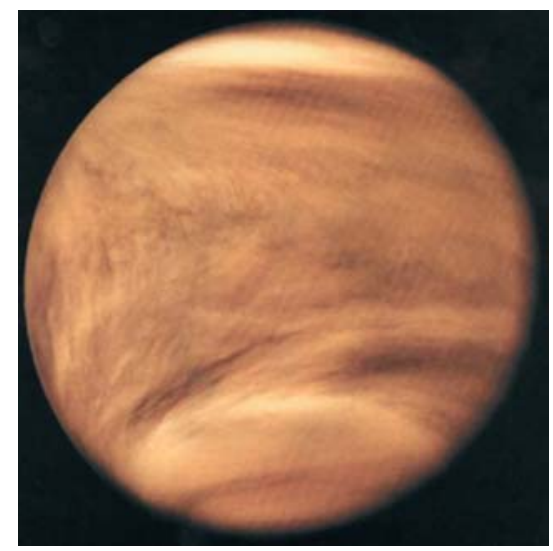

Fig. 4 Ultraviolet image of Venus' clouds as seen by the Pioneer Venus Orbiter (Feb. 5, 1979). Venus appears in reflected UV light. Dark areas trace cloud top winds and are produced by absorption of solar UV below by $\mathrm{SO}_{2}$ and most likely various allotropes of sulphur. Source: NSSDC, http://nssdc.gsfc.nasa.gov/photo_gallery/ photogallery-venus.html, image pvo_uv_790205

pothesize that the young outflow processes and volcanism are genetically related to other very young water-related landforms. The latter include the gullies, a thin ice-rich mantling layer covering about $23 \%$ of Mars (Kreslavsky and Head 2002), and perhaps some of the dark slope streaks on Martian hillslopes, at which shallow water is possibly being mobilized (Ferris et al. 2002; Miyamoto et al. 2004b). The genetic connection for all these phenomena might well be climate change, induced by the water vapor and gases introduced to the atmosphere by both flooding and volcanism. This would explain the recent detection by neutron and gamma-ray instruments of a near-surface zone of water-ice abundance at high Mars latitudes (Boynton et al. 2002). That water may reflect very recent emplacement during the same aqueous episode. However, it is also important to note that orbital parameters, such as change in obliquity, may help explain glaciation reportedly to have occurred within approximately the last 2.1 million years of the history of Mars (Head et al. 2003).

\section{Venus}

The present climate of Venus does not have a hydrological cycle. The climate is controlled by a carbon-dioxidewater greenhouse effect and the radiative properties of its global cloud cover (Bullock and Grinspoon 2001; Fig. 4). The Venusian surface is extremely desiccated with water existing neither in vapor form nor in the liquid state, because ambient surface temperatures are about $460^{\circ} \mathrm{C}$ (Fig. 5). Channels and valleys have been documented for Venus (e.g., Baker et al. 1992b; Komatsu et al. 1993, 2001), and hypothesized to have a volcanic origin in general, though some channels (canali) have been argued by others to be water-related (e.g., Jones and Pickering 2003). Liquid water may exist, however, in the subsurface of Venus under supercritical conditions. Although there is 


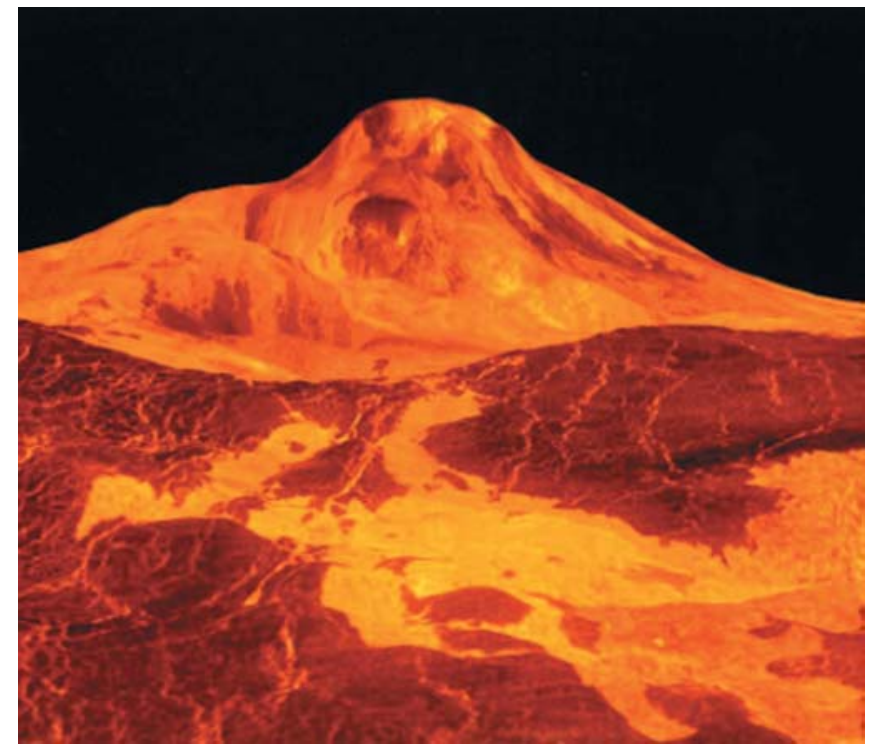

Fig. 5 Venusian surface. Maat Mons is displayed in this threedimensional perspective view of the surface of Venus. The viewpoint is located $560 \mathrm{~km}$ north of Maat Mons at an elevation of $1.7 \mathrm{~km}$ above the terrain. Lava flows extend for hundreds of kilometers across the fractured plains (foreground) to the base of Maat Mons. The view is to the south towards Maat Mons (background), an 8-km-high volcano, which is located at approximately $0.9^{\circ}$ north latitude, $194.5^{\circ}$ east longitude. Magellan synthetic aperture radar data is combined with radar altimetry to develop a three-dimensional map of the surface. Rays cast in a computer intersect the surface to create a three-dimensional perspective view. Simulated color and a digital elevation map, developed by the U.S. Geological Survey, are used to enhance small-scale structures. The simulated hues are based on color images recorded by the Soviet Venera 13 and 14 spacecraft. The image was produced at the U.S. National Aeronautics and Space Administration/Jet Propulsion Laboratory Multimission Image Processing Laboratory. Source: National Space Science Data Center, http://nsdc.gsfc.nasa.gov/image/planetary/venus/mgn_maat_mons.jpg

no hydrological cycle on Venus today, a hydrological cycle may have existed in the past. Based on the high deuterium/hydrogen ratio of the lower atmosphere (Volkov et al. 1986), the evolution of $\mathrm{H}_{2} \mathrm{O}-\mathrm{CO}_{2}$ atmospheres (Abe and Matsui 1988), and the amount of ${ }^{40} \mathrm{Ar}$ present in the atmosphere (Matsui and Tajika 1991), it is likely that a proto-ocean and a hydrological cycle existed on early Venus. A warm ocean may have existed for several hundred million years or longer until it evaporated away due to a run-away moist greenhouse effect and an increase in solar luminosity (Kasting 1988). The reduction in surface water would have prevented the formation of carbonates, allowing $\mathrm{CO}_{2}$ partial pressures to increase by volcanic outgassing, further increasing the greenhouse effect (Cockell 1999). Eventually, the evaporated water dissociated in the atmosphere under the influence of radiation. The hydrogen was lost to space and the oxygen formed sulfur oxides in the atmosphere and various oxides with surface rocks. Today, Venus is enveloped by a 92 bar thick carbon dioxide-nitrogen atmosphere with little remaining water. All the water left at Venus is present in minute amounts in the atmosphere and possibly in liquid form (supercritical) in the subsurface.

Water vapor concentrations measured by various probes have been inconsistent, but concentrations appear to be highest in the lower cloud layer at an altitude of $50 \mathrm{~km}$ with a concentration of a few hundred parts per million (Florensky et al. 1978; Krasnopolsky 1986; Fegley and Treiman 1992). Most of the available water in the atmosphere is likely bound to sulfur compounds in a form such as $\left[\mathrm{H}_{2} \mathrm{SO}_{4} \times n\left(\mathrm{H}_{2} \mathrm{O}\right)\right]$. A large number of particulates occur in the Venusian global cloud layers, most remarkable being the several- micrometer-large particles in the lower cloud layer, which have been proposed to possibly represent microbial cells enveloped in a sulfur coating (Grinspoon 1997; Schulze-Makuch and Irwin 2002a, 2004; Schulze-Makuch et al. 2004). The chemistry of the atmospheric water is unclear at this point. The water vapor should be quite acidic with a $\mathrm{pH}$ of about 0 with sulfate being the most common anion. $\mathrm{HCl}$ and $\mathrm{HF}$ have been detected as trace compounds. Cockell (1999) pointed out that the water vapor should also contain significant amounts of carbon, nitrogen and phosphorus. Perturbations in the abundance of atmospheric water vapor and the sulfur gases (e.g. $\mathrm{SO}_{2}, \mathrm{COS}, \mathrm{H}_{2} \mathrm{~S}$ ) affect greatly the greenhouse effect and the Venusian clouds, and ultimately result in climatic changes (Bullock and Grinspoon 2001).

The presence of liquid supercritical water in the subsurface of Venus has been speculated upon (SchulzeMakuch and Irwin 2002a). This speculation is based on liquidus curves of water that indicate that pressures only slightly higher than those currently present on the Venusian surface would be needed to obtain water in liquid form. This postulation is further supported by the observation that water is a major constituent of magmatic volatiles. Observed deposits of explosive eruptions on the Venusian surface (e.g. the Sapho Patera region) in a dense, hot atmosphere would require high abundances of magmatic volatiles to overcome the atmospheric pressure. However, rocks on the surface are extremely desiccated, and if they contained water, they must have lost it in short time periods. If liquid water were present in the subsurface of Venus it would be in a supercritical state with properties quite different from thermodynamically stable water.

\section{Mercury}

Mercury's conditions are extremely harsh. The planet is closer to the Sun, and thus during its embryonic stage of formation is expected to have received smaller amounts of volatile compounds than the rest of the terrestrial planets. Near its poles, frozen water ice has been discovered within permanently shadowed impact craters (Slade et al. 1992), where volatiles are stable for long periods of time at temperatures of about $112^{\circ} \mathrm{K}$. The area covered by the ice deposits is estimated to be about $3 \times 10^{14} \mathrm{~cm}^{2}$. For a $2-20 \mathrm{~m}$ thick deposit this would be 40 
$800 \mathrm{~km}^{3}$. Though the ice probably originated from relatively recent comet impacts, it may be possible that the remnant waters could archive early solar system information if the impacts and partial water infilling occurred relatively early in the development of Mercury (i.e., shortly after the formation and hardening of the crust). Considering the latter case, this water ice may contain some clues about the materials that protected and catalyzed the first biological synthesis on Earth.

\section{The Moon}

The Moon is thought to have formed 4.5 billion years ago by a gigantic impact of a Mars-sized body with the Earth (Cameron and Benz 1991). This model explains the high spin of the Earth-Moon system, the inclined lunar orbit, the moon's low density compared to that of the Earth, and the very low volatile and high refractory elemental abundances. Because of the Moon's origin, lunar rocks have essentially no water, bound or otherwise. The physical processes, which produce the extremely thin lunar atmosphere (only $10^{13}$ molecules $/ \mathrm{m}^{3}$ for the surface number density of atoms in the daytime), include sputtering by solar wind ions, vaporization of lunar surface materials due to such as meteoroid impact, and outgassing from the surface, as on Mercury. Thus, the Moon never had oceans or lakes on its surface, and it never had subsurface water. Any water in the original rocks that formed the Moon was lost in the impact process. Like Mercury, the Moon has polar ice deposits in the permanently shadowed areas of craters in the polar regions (Feldman et al. 2001). However, the deposits are considerably smaller than Mercury's, with an ice concentration of only about $1.5 \%$ weight fraction. As on Mercury, the water is probably derived from comet impacts.

\section{Outer solar system planetary bodies}

\section{The possibility of a subsurface ocean on Jupiter's moon Europa}

The presence of an ocean beneath Europa's icy crust can be inferred from the observations of (1) magnetic fields induced by eddy currents in a mobile conducting medium within the body of the satellite (Khurana et al. 1998), (2) asynchronous rotation of Europa that implies a friction generated subsurface material (Geissler et al. 1998), and (3) a diverse array of evidence, including fractures that are interpreted to result from mobile icebergs driven by subsurface liquid (Carr et al. 1998; Hoppa et al. 1999), surfaces that are geologically young (Moore et al. 1998a), chaotic terrain that comprise small rotated and tilted blocks interpreted to result from the deformation of an ice crust (Head and Pappalardo 1999), and bands interpreted to result from extensional processes (Pappalardo et al. 1999; e.g., Figs. 6 and 7). The presence of an ocean below an icy crust is also consistent with models for the origin of the larger outer satellites of Jupiter (Consolmagno and
Lewis 1976). Furthermore, Doppler tracking of the Galileo spacecraft suggests that Europa has a differentiated internal structure, which includes a dense core of metal or metal sulfides, a rocky mantle, and a low-density ice crust or ice-crusted ocean with a thickness of $80-170 \mathrm{~km}$ (Anderson et al. 1998). Europa's metallic core can be assumed to provide internal heat through radioactive decay, subjecting the ocean floor to volcanic eruptions (Schulze-Makuch and Irwin 2002b).

The deep ocean environment on Europa may resemble that on Earth where hydrothermal discharge areas on the aphotic ocean bottom support hydrothermal vent communities (Vinogradov et al. 1996; Amend and Shock 1998). Given the great depth of the ocean, considerable ionic and osmotic gradients could extend from the ocean floor upward. Near the surface, the interface between ice and liquid on the underside of the ice sheet, as well as liquid inclusions within the ice itself, could generate steep local osmotic and ionic gradients (Schulze-Makuch and Irwin 2002b). Endogenic heat flow to the icy surface is indicated by the observation of systematic post-sunset temperature variations with latitudes: northern latitudes are warmer than equivalent southern latitudes and there is a temperature minimum along the equator (Spencer et al. 1999). Though it is relatively small (a radius of $1,569 \mathrm{~km}$ ), dominantly tidal friction and possible endogenic heating related to radioactive decay provide sufficient internal heat to keep the ocean liquid, as well as allowing crustal melt to occur and crustal thickness to vary.

The chaotic terrain is one of the major types of geologic terrains on Europa (Fig. 7). Typically it has been thermally disrupted, leaving a lumpy matrix with somewhat displaced rafts (Greenberg and Geissler 2002). Chaotic terrain is very common. Based on the limited portion $(\sim 10 \%)$ of the surface image, Riley et al. (2000) found that nearly half of Europa's surface is chaotic terrain, while the other half is covered by tectonic terrain. The chaotic terrain on the surface of Europa is interpreted by McKinnon (1999) to result from convection. Thus, large convection cells can be inferred to exist in Europa's ocean that could circulate water from the warm bottom areas of the ocean to just beneath Europa's icy crust, which is in contact with space. These convection currents would be generated from the thermal differentials between the ice-covered surface and the geothermally heated ocean floor. Currents may also be generated within tidal channels either on the ocean floor or in the ice ceiling due to Jupiter's strong gravitational attraction, which is in alternating synchrony or opposition to the other Jovian satellites.

The saline content of Europa's ocean is unknown, but both surface coloration on the ice and results from modeling the lunar evolution of Europa suggest that it could be high. Several systems were advanced such as a Na$\mathrm{Mg}-\mathrm{Ca}-\mathrm{SO}_{4}-\mathrm{Cl}-\mathrm{H}_{2} \mathrm{O}$ with a neutral $\mathrm{pH}$ (Kargel et al. 2000), a Na-K-Cl-SO $\mathrm{S}_{4}-\mathrm{CO}_{3}-\mathrm{H}_{2} \mathrm{O}$ system with an alkaline $\mathrm{pH}$ (Marion 2001), and a Na-H-Mg-SO $\mathrm{S}_{4}-\mathrm{H}_{2} \mathrm{O}$ system with an acidic pH (Marion 2002). These models all have sul- 


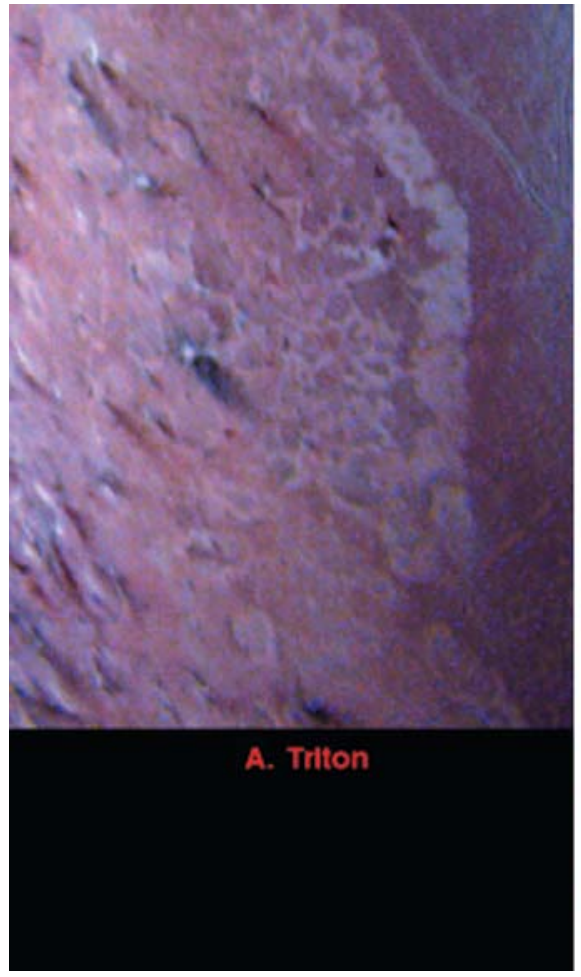

Fig. 6 A Triton's surface as seen from Voyager 2. Source: http:// www.ias.fr/cdp/site_aurores/surface_Triton.jpg. (B) Europa's surface. False color has been used here to enhance the visibility of certain features in this composite of three images of the Minos Linea region on Jupiter's moon Europa taken on 28 June 1996 Universal Time by the solid state imaging camera on NASA's Galileo spacecraft. Triple bands, lineae and mottled terrains appear in brown and reddish hues, indicating the presence of contaminants in the ice. The icy plains, shown here in bluish hues, subdivide into

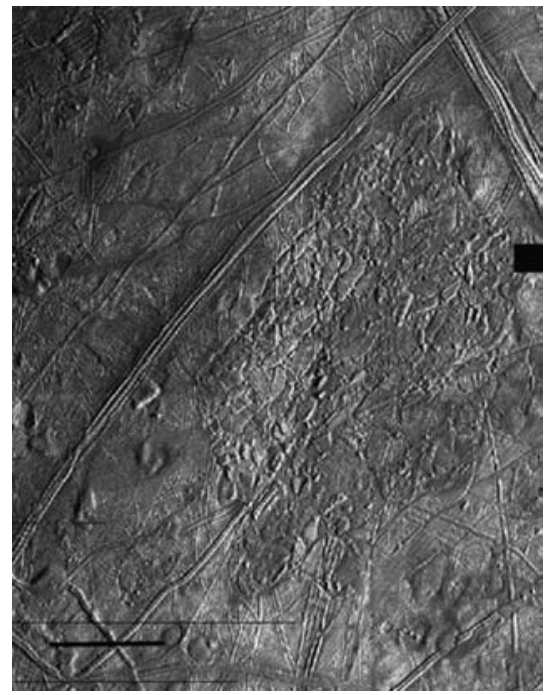

Fig. 7 Shown is an example of chaotic terrain, Conamara Chaos, located at $8^{\circ} \mathrm{N}, 274^{\circ} \mathrm{W}$ on Europa (scale bar equals $20 \mathrm{~km}$; Images from orbit E6, 383713713, 383713726, and 383713765)

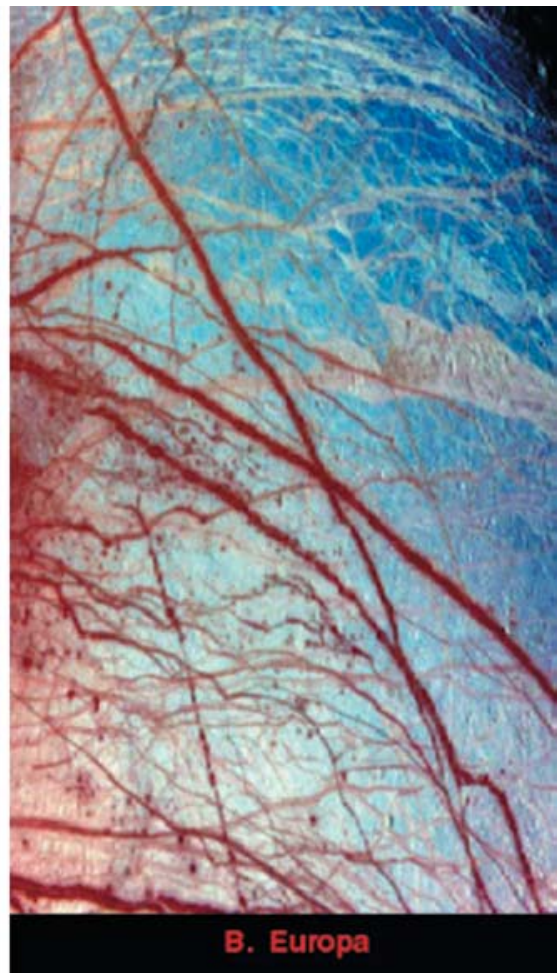

units with different albedos at infrared wavelengths probably because of differences in the grain size of the ice. The composite was produced using images with effective wavelengths at 989,757 , and 559 nanometers. The spatial resolution in the individual images ranges from 1.6 to $3.3 \mathrm{~km}$ per pixel. The image is centered at $45^{\circ} \mathrm{N}$, $221^{\circ} \mathrm{W}$, and it measures approximately $1,260 \mathrm{~km}$ across. Source: National Space Science Data Center, http://nssdc.gsfc.nasa.gov/ image/planetary/jupiter/gal_eu1_47906.jpg

fate as the most common anion. Remote sensing of the surface of Europa with near-infrared instruments revealed the presence of hydrated materials, including sulfate salts (Dalton 2003), which appears to support this notion. However, the sulfates could have originated from other sulfur compounds that were later oxidized by radiation. For example, McKinnon and Zolensky (2003) point out that Europa's primordial ocean was most likely sulfidic. A reducing ocean bottom on Europa is likely, although enough oxygen for a significant redox-gradient in Europa's ocean may be provided by the natural dissociation of water and by the seeping of oxidants through Europa's icy crust.

Chyba (2000) proposed that disequilibrium chemistry in Europa's ice cover could produce enough organic and oxidant molecules to fuel a Europan biosphere. Highly oxidized compounds such as $\mathrm{H}_{2} \mathrm{O}_{2}$ have been identified on the ice crust (Carlson et al. 1999). If these oxidants seep into the ocean, then a significant redox-gradient, ranging from a very reducing milieu near the ocean floor to a slightly oxidizing milieu near the ocean's interface with the ice crust, could be created. If a redox-gradient is present, the prospects for life are raised substantially because of the potential for stable chemical cycles. By using 
reasonable assumptions about the environmental conditions, nutrient cycling, and available energy sources in Europa's ocean, Chyba and Philipps (2002), Zolotov and Shock (2003), and Irwin and Schulze-Makuch (2003) showed that the ocean could in principle support a significant amount of biomass. Each of these modeling studies used different energy sources for biosystem support such as oxidative metabolism driven by the radiolytic production of oxygen; biogenic sulfate reduction, and methanogenesis driven by the outgassing of hydrogen, respectively.

The possibility of a biosphere in fracture zones within the ice crust has drawn much less attention, although this remains a possibility. Brines are enriched in salt content during differential freezing, and Earth organisms are known to be able to survive and reproduce in extremely saline environments. Brines can substantially lower the temperature at which the ice freezes and some ammonia mixed into the water would lower the freezing temperature further, although it is unclear whether this would be sufficient for Europan conditions. Another potential limiting factor is radiation. Europa lies deep within the magnetosphere of Jupiter and is continuously bombarded with magnetically trapped, ionizing radiation (BaumstarkKhan and Facius 2002; Marion et al. 2003). Possible life forms and organic compounds are adversely affected by the surface radiation (Greenberg et al. 2002). However, the ice would be a favorable medium for preserving life and organic compounds if suitable microenvironments occur far enough below the surface ice. In this case, the ice could provide some protection for active life in brine entrapments, yet some organisms might benefit from photosynthesis (Greenberg and Geissler 2002).

\section{Subsurface oceans in Ganymede and Callisto}

Aside from Europa, the two other big icy satellites of Jupiter, Ganymede and Callisto (Fig. 8), may also hold subsurface oceans. Their mean densities are, respectively, 1.94 and $1.84 \mathrm{~g} / \mathrm{cm}^{3}$, and increase with increasing depth, suggesting that they are composed of silicates and water in the same proportion, and more or less differentiated into inner cores, convecting mantles and outer rigid crusts (Showman and Malhotra 1999). The crusts of Ganymede and Callisto can be resistant to internal heat loss by convection (Ruiz 2001), thus maintaining the heat generated by the decay of radioactive elements in the core, and keeping an ancient liquid-water ocean from freezing in the interior. The addition of antifreeze substances that reduce the freezing point of water ice (e.g., ammonia hydrates and/or salts, see Cassen et al. 1982; Stevenson 1998, Kargel et al. 2000) would also help to maintain the inner oceans.

Ganymede is the Solar System's largest satellite, comparable in size to Mercury, with a complex geologic history reflected on its surface. The rocky core is probably as big as half of the total diameter of the moon, and it is probably differentiated, with an inner metallic core. The surface shows a dark ancient terrain, comprising about $34 \%$ of its surface, composed of ice and silicates, and
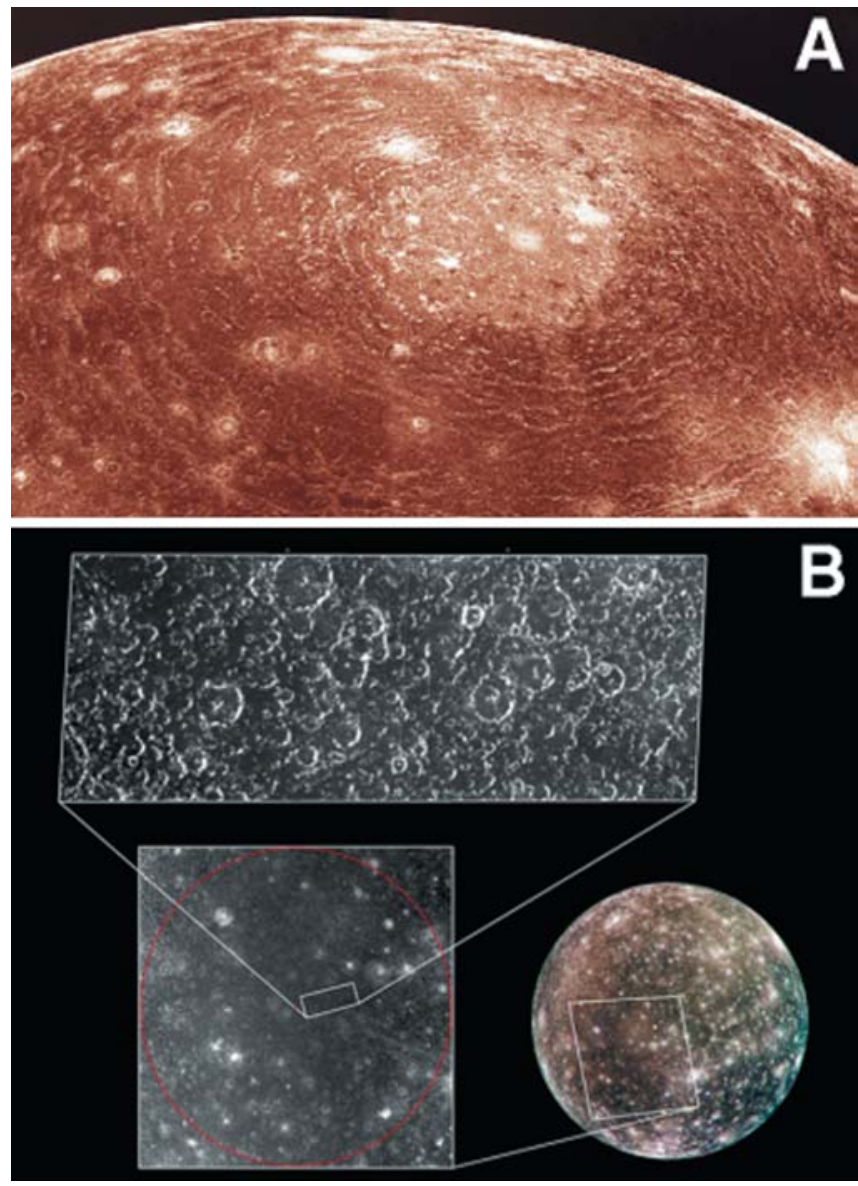

Fig. 8 Callisto's Valhalla impact basin (A) and its antipodal area (B), where neither grooved nor hilly terrain are noted, supporting the hypothesis of a subsurface ocean that dissipated the seismic waves caused by the impact. (A) Voyager 1 image processed by C.J. Hamilton. (B) Galileo image PIA-02593; NASA/JPL/ASU

densely cratered. The opposite face is a much younger bright terrain, probably reshaped by tectonic and volcanic activity (Smith et al. 1979), and flooded by low-viscosity aqueous lavas, which are subsequently frozen (Schenk et al. 2001). In any case, the surface is covered with water ice in a proportion of up to $90 \%$ ice by mass (McKinnon and Parmentier 1986), with the addition of hydrated salt minerals, mostly $\mathrm{MgSO}_{4}$, derived from a subsurface brine-laden ocean (McCord et al. 2001).

In addition to antifreeze substances, the tidal heating induced by the proximity of Jupiter may also contribute to the stability of Ganymede's inner ocean by reducing ice viscosity (McKinnon 1999), and may be a compelling explanation for the young appearance of the brighter terrains. The internal ocean, however, would have remained stable although the tidal stress could have allowed the onset of convection, as tidal heating in the outer shell of Ganymede can stabilize an ice shell 20-90 km thick (Ruiz and Fairén 2002; Fairén and Ruiz 2003). In addition, data from Galileo spacecraft strongly argues for the ocean to exist: magnetometer data confirmed the presence of a magnetic field in Ganymede (Kivelson et al. 1998), 
indicating that the heat released from the moon's interior is large enough to create an inner molten core sustaining a core dynamo, and thus the heat can also melt part of the ice inside Ganymede. Alternatively, the magnetic field may be generated by dynamo action on the salty ocean.

Callisto is only slightly smaller than Ganymede and has a similar mean density $\left(1.83 \mathrm{~kg} / \mathrm{m}^{3}\right)$; however, its internal structure is very different from that of Ganymede due to the significant difference in the nomalized axial moment of inertia. The central silicate core of Callisto may occupy up to 50\% of the moon's radius (Anderson et al. 2001). Its surface contains an average of 50\% ice, including low albedo features that imply contamination by darker materials (Showman and Malhotra 1999). The population of small craters is lower than that in Ganymede, but the population of larger craters is higher, so some kind of erosional process is occurring on the smaller craters, perhaps driven by sublimation of $\mathrm{CO}_{2}$ or ammonia (Moore et al. 1998b).

The case for an ocean within Callisto has been supported strongly both by models of heat convection impeding heat flow (Ruiz 2001) and magnetometric data explained by a dynamo effect stemming from electronic conductivity of salty water (Khurana et al. 1998). There is also indirect geological evidence for the ocean: Voyager and Galileo mission image analyses demonstrated that Callisto is the most densely cratered object in the Solar System, with no volcanic or tectonic landforms, and with a crust age dating back as far as 4 Gyr. The antipodal zone of the greatest impact crater, Valhalla, is indistinguishable from the rest of the surface, whereas in similar-sized bodies such as Mercury or the Moon impacts of comparable magnitude always create important tectonic deformations and hummocky terrains in the surface crust of the crater antipode, suggesting that the subsurface ocean absorbed the impact energy and then dissipated the seismic waves (Watts et al. 1991; Williams et al. 2001). Possibly, the ocean is generated by the decay of radioactive elements, is some $20 \mathrm{~km}$ thick, and stays hidden $100 \mathrm{~km}$ below the surface, comprised between two great ice layers (two solid convecting regions, Khurana et al. 1998) that preclude heat circulation. Nevertheless, heat plumes from the silicate interior could reach the ocean through the inner ice layer, chemically enriching Callisto's inner liquid water.

\section{Titan-a hydrological cycle without water?}

Titan is the largest moon of Saturn's many satellites and the only moon in the solar system with a thick atmosphere. Titan's atmosphere is 1.5 bar thicker than Earth's atmosphere, but surface temperatures reach only about $95^{\circ} \mathrm{K}$. The reducing atmospheric consisting primarily of nitrogen and methane is similar to the one which is believed to have existed on early Earth. Thus, conditions on an earlier and expectedly warmer Titan shortly after its formation may have been much more benign resembling conditions of Earth at that time. Though polymeric chemistry has not been confirmed yet for Titan, it is most likely present given the complex carbon chemistry in
Titan's atmosphere and on its surface (Khare et al. 1986; Sagan et al. 1992, 1993). An abundant energy source is present at least in the form of UV radiation and photochemistry. The question of volcanic activity has not been resolved yet. Titan has an overall low density of 1.88 , which would imply that solid substrate is quite rare at the surface. The relative lack of heavy elements may cause less radioactivity and with it less volcanism and less heat. Nevertheless, the geothermal heat flow on Titan has been estimated as $4 \mathrm{~m} \mathrm{Wm}^{-2}$ (Lorenz and Shandera 2001), which would suggest the presence of some volcanic activity. If significant, it would increase the chances for liquid water and life on Titan by providing potentially habitable geothermal areas (Schulze-Makuch and Abbas, 2004).

On Titan, unlike Earth, the requirement for the presence of a liquid solvent is not restricted to water. The functions of a solvent include (1) to provide an environment that allows for the stability of some chemical bonds to maintain macromolecular structure, while (2) promoting the dissolution of other chemical bonds with sufficient ease to enable frequent chemical interchange and energy transformations from one molecular state to another; (3) the ability to dissolve many solutes while enabling some macromolecules to resist dissolution, thereby providing boundaries, surfaces, interfaces, and stereochemical stability; (4) a density sufficient to maintain critical concentrations of reactants and constrain their dispersal; (5) a medium that provides both an upper and lower limit to the temperatures and pressures at which biochemical reactions operate, thereby funneling the evolution of metabolic pathways into a narrower range optimized for multiple interactions; and (6) to function as a buffer against environmental fluctuations (Schulze-Makuch and Irwin 2004). Fortes (2000) suggested that a subsurface ocean may exist on Titan consisting of an ammonia-water mixture. Ammonia mixed with water in the subsurface would act as "antifreeze", thus allowing a putative ocean to stay liquid at much lower temperatures. Implications for possible life would be similar to the putative subsurface oceans on Europa, Ganymede, and Callisto, as discussed above.

While a polar ammonia-water mixture may be present as a solvent in Titan's subsurface, ethane and methane are available as non-polar solvents on Titan's surface. A methane cycle may exist on Titan with some similarities to the hydrological cycle on Earth. Methane clouds have been detected at Titan recently (Roe et al. 2002), and methane rain is consistent with modeling results (Tokano et al. 2001; Chanover et al. 2003). Jakosky (1998) suggested that the predicted surface reservoirs or oceans are composed mainly of an ethane-methane mixture and trace dissolved $\mathrm{N}_{2}$. Due to its higher specific gravity, solid acetylene would be present on the bottom of these reservoirs and usable as an energy source for various chemical reactions involving a multitude of organic compounds. Regions of geothermal activity have been suggested to exist on Titan (e.g. Lorenz 2002), and if existent, could provide the necessary energy to accelerate 
Fig. 9 General environment of Titan; schematic modified from Schulze-Makuch and Abbas (2004)

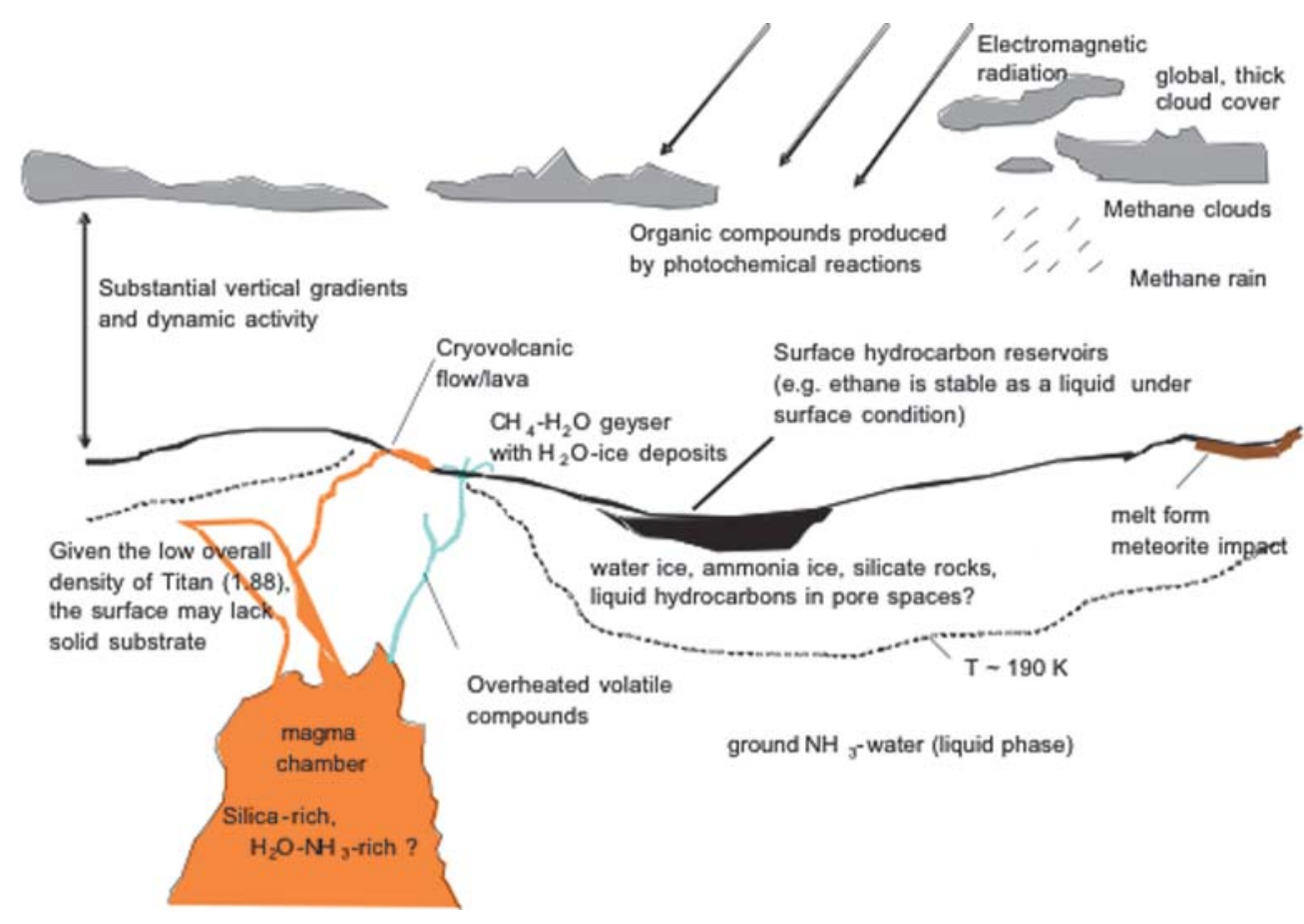

reactions to a reasonable pace. The most likely energy sources providing heat to the surface would be aqueous volcanism or meteorite impacts. Both mechanisms may have created episodes of aqueous chemistry in lakes on Titan's surface, perhaps lasting thousands of years before freezing over (Lorenz et al. 2000). An especially promising environment for life would thus be a hot spring or geothermal area at the bottom of a hydrocarbon reservoir (Fig. 9). This environment would not only provide a versatile suite of raw material for organic synthesis and some amount of liquid water and ammonia for organic reactions, but also high enough temperatures for reactions to occur rapidly (Schulze-Makuch and Abbas, 2004). If this site would include microenvironments with fluid/ solid interfaces, zones of fluid accumulation or entrapment, and areas enriched with material that could act as a catalyst (e.g. zeolites, clay), it would be especially favorable for biology (Khare et al. 1986; Sagan et al. 1992, 1993; Dermott and Sagan 1995).

\section{Triton and the Neptunian system}

Orbiting Neptune is Triton, the only big satellite in the Solar System rotating retrograde (Fig. 6). Its density is much higher that those of the rest of the icy satellites of Saturn and Uranus $\left(>2 \mathrm{~g} / \mathrm{cm}^{3}\right)$, suggesting a big rocky nucleus. Together, these two characteristics suggest that Triton was an independent heliocentric body, probably from the family of the Edgeworth-Kuiper Belt Objects, gravitationally captured by Neptune thousands of millions of years ago (see McKinnon et al. 1995, for a comprehensive review of this topic). On its surface of nitrogen ice with traces of methane, carbon monoxide, and carbon dioxide (Cruikshank et al. 1993), craterization rates suggest very recent crustal recycling processes. In addition, long-lasting active geysers on the surface resulting in gas decompression belch out liquid nitrogen and dust particles (methane, organic polymers, hydrocarbons) to the very tenuous $\mathrm{N}_{2}$ atmosphere (16 $\mu$ bar), which incorporates thin clouds of nitrogen ice crystals (Soderblom et al. 1990).

Thomson and Sagan (1990) described that during the local cold season (lasting about 80 Earth-years), nitrogen, methane, and other simple hydrocarbon species snows are radiated by the particles captured in Neptune's magnetic field and are then colored in a pale yellow to peach contrasting with the bright white of the surface. The UV radiation, moreover, drives chemical reactions transforming the snow in complex organic molecules, mainly nitriles and hydrocarbons resulting from the dissociation of $\mathrm{N}_{2}$ and $\mathrm{CH}_{4}$, respectively, and producing chromophores. These are deposited on the surface during the milder season, while the snows migrate to the opposite hemisphere. Over the lifetime of Triton, a 6-m-thick layer of sediments of hydrocarbons (Cruikshank et al. 1993) may have been formed by the accumulation of the same kind of molecules that participated in the origin of life in the Earth more than 4 Gyr ago. Triton is the coldest body in the Solar System, with a mean temperature of $38^{\circ} \mathrm{K}$, maintained constant by the sublimation and condensation of nitrogen (Elliot et al. 1998). Nevertheless, it may harbour an inner ocean, hidden at a depth of about $100 \mathrm{~km}$ under the nitrogen-ice surface. The surface layer has a very low thermal conductivity, acting as a thermal insulator (McKinnon et al. 1995) due to its composition of water ice and nitrogen-, carbon monoxide-, carbon dioxide- and methane-ices, which have a thermal conductivity lower than water ice (Ross and Kargel 1998). The maintaining of the inner heat favors the existence of an inner ocean, probably not deeper than 350-400 km (Smith 


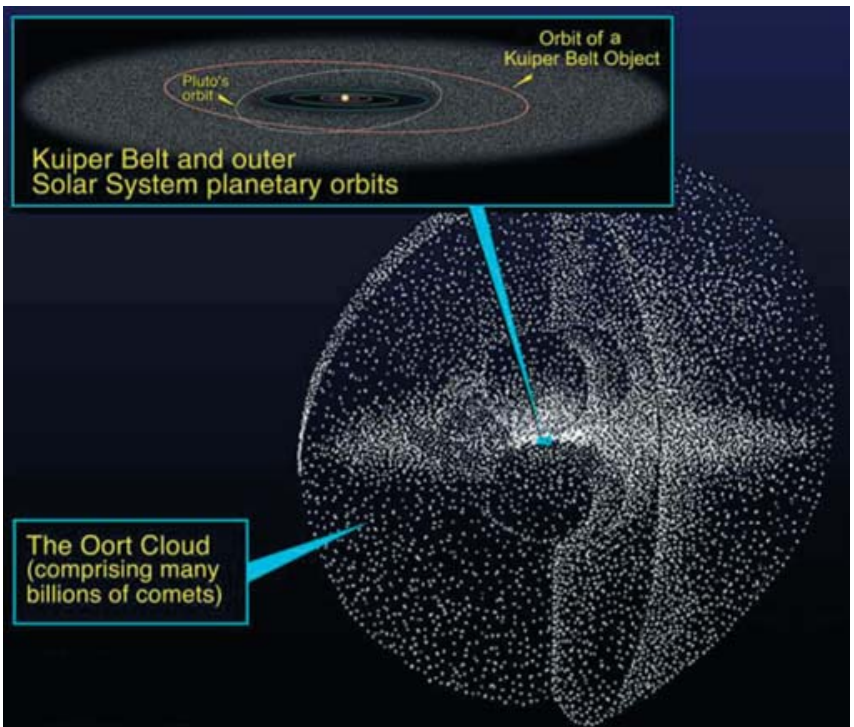

Fig. 10 Situation of the Edgeworth-Kuiper Belt and the Oort cloud surrounding the Sun's planetary system (Donald K. Yeoman, JPL)

et al. 1989; McKinnon et al. 1995) or 200-300 km (Ruiz and Fairén 2002; Fairén and Ruiz 2003). But the stability of the inner ocean may be reached at depths no greater than $30-40 \mathrm{~km}$ if the ice contains ammonia: the possible inner ocean of Triton, as argued for Ganymede and Callisto, would also need the incorporation of antifreeze substances to maintain its stability, as ammonia lowers the water ice fusion point to $176^{\circ} \mathrm{K}$.

Incomparably wider may be the ocean of Neptune (Hubbard 1984; Miner and Wessen 2002): over the rocky nucleus, almost the size of the Earth, may be an immense liquid-water ocean mixed with silicates, methane, and ammonia, extending up to the atmosphere of hydrogen, helium, and methane. The ocean must be extremely hot, about $5,000^{\circ} \mathrm{K}$, remaining liquid as a consequence of the high pressure.

\section{Edgeworth-Kuiper Belt objects}

Orbiting 4,600 km away from the Sun, Pluto is a great object from the Edgeworth-Kuiper Belt (EKBOs; see Edgeworth 1943, 1949; Kuiper 1951; Jewitt and Luu 1993), a population of objects stored at 30-60 K, including $>10^{8}$ larger than $10 \mathrm{~km}$ in diameter (Cochran et al. 1995), beyond the orbit of Neptune (Fig. 10). Pluto's mean density, $1.85 \mathrm{~g} / \mathrm{cm}^{3}$, is similar to that of Ganymede and Callisto, thus suggesting that water is also an important component. In fact, the presence of amorphous water ice in some small bodies of the outer Solar System has been detected, as for example in the Centaurs Pholus and 1997 CU26 (Brown et al. 1998). Centaurs are assumed to have originated in the Edgeworth-Kuiper Belt (Edgeworth 1949; Kuiper 1951; Irwin et al. 1995); so, if a similar composition is assumed for the rest of the EKBOs, tidal forces operating between some of them could promote the fusion of ice and the stability of inner liquidwater oceans. This possibility is enhanced in the Pluto-
Charon system, as they are orbiting very close. Furthermore, the same tidal forces can induce volcanic phenomena on their rocky nucleus, similar to those in Io, creating environments as interesting from a biological point of view as the bottom of the Earth's oceans.

As said for other objects, the addition of ammonia could also help to maintain water in the liquid state. Furthermore, the detection of $\mathrm{CH}_{4}$ (both free and dissolved in molecular nitrogen) and $\mathrm{N}_{2}$ has been possible in Pluto and Triton, and in object $1993 \mathrm{SC}$; as well as other simple hydrocarbons such as $\mathrm{C}_{2} \mathrm{H}_{2}, \mathrm{C}_{2} \mathrm{H}_{4}$, or $\mathrm{C}_{2} \mathrm{H}_{6}$, and complex hydrocarbons (Brown et al. 1997). Furthermore, Pholus may also hold some light organic material such as ethanol (Brown et al. 1998). The distinct substance dominating the spectrum in Pluto, Pholus, object 1997 CU26, or object 1993 SC, may be a sign of their different compositions and thermal evolutions: neither the EKBOs nor the Oort cloud comets can be considered wholly pristine, but slightly geologically evolved (Stern 2003). NASA is now projecting the mission "New Horizons" to study the far Solar System in 2020, including flybys over Pluto, Charon and other EKBOs.

\section{Comets and the origin of water in the planets of the solar system}

Cometary ices consist basically of $\mathrm{H}_{2} \mathrm{O}$ ice, with minor amounts of $\mathrm{CO}_{2}, \mathrm{CO}, \mathrm{H}_{2} \mathrm{~S}, \mathrm{CH}_{3} \mathrm{OH}, \mathrm{H}_{2} \mathrm{CO}, \mathrm{NH}_{3}, \mathrm{HCN}$, $\mathrm{CH}_{4}$, and $\mathrm{S}_{2}$, and most of them derive from a spherical shell surrounding the Solar System at a distance from the Sun of $10^{4}-10^{5}$ A.U., named the Oort cloud (Oort 1950), where up to $10^{12}$ cometary nuclei may be stored (Weissman 1996). Also, a minor but significant proportion of comets exist in the Edgeworth-Kuiper Belt.

The majority of the long-period comets (periods $>200$ years) currently crossing the Solar System come from stable orbits originated in the Oort cloud, such as Halley, Hyakutake, and Hale-Bopp. They are extremely cold bodies, preserved at ambient temperature of $5^{\circ}-6^{\circ} \mathrm{K}$, which are destroyed in a proportion up to $99 \%$ before completing half a dozen orbits, due to the big thermal shock caused in their movementto the inner and warmer regions of the Solar System (Levison et al. 2002). Compositions include water chemically distinguishable from that of the Earth's oceans. This has been argued to put into question the role of such comets as conveyors of water to the planetary surfaces, as advanced by Oró (1961), who proposed that the primitive oceans on Earth were formed from cometary water.

But it is possible that there was another big population of comets in the early times of the Solar System history. The analysis of the ice of the C/1999 S4 LINEAR comet has revealed a deuterium/hydrogen proportion virtually identical to that in the terrestrial oceans (Mumma et al. 2001). Thus, it has been proposed that the origin of LINEAR was close to the orbit of Jupiter, a region where the majority of the comets may have formed $4.5 \mathrm{Gyr}$. ago, as there was then concentrated the majority of the protoplanetary material. With time, Jupiter's gravity expelled almost every comet far away from its orbit, and some fell 
over the rocky worlds, and the rest escaped to the interstellar space. In its nucleus, LINEAR holds near 3.5 million tons of water (Mäkinen et al. 2001). When LINEAR entered the inner Solar System, the thermal shock was limited; but the heat may have activated a number of chemical reactions, and so LINEAR incorporates a great quantity of complex organic molecules, much more than in the Oort's comets. It is very likely that bodies similar to LINEAR seeded the inner planets with water and organics during the Heavy Bombardment phase of solar system evolution (prior to about 3.9 billion years ago).

\section{Exoplanets}

The putative hydrological cycle seems to have been quite different for each of the rocky planets and the many satellites of the Solar System. Theoretically, a similar degree of variability is expected to be discovered in the future exploration of extra-solar systems. Although today the direct exploration of exoplanets is well beyond the capabilities of science, their existence has been confirmed recently (i.e., Mayor and Queloz 1995; Lissauer 1999; Throop et al. 2001; Ford et al. 2001; Konacki et al. 2003).

As a consequence of the inherent limitations to a nascent technique, the exoplanets described so far are those which highly alter the orbital parameters of their stars, i.e., they are gas giants with a mass ranging from 0.1 to 10 Jupiter masses, and with highly elliptical orbits very close to their parent stars (Irion 2004). Probably, most extrasolar systems also have "standard" Jupiters. These are hydrologically significant in that they may harbour immense inner oceans, such as those in Neptune (Hubbard 1984; Miner and Wessen 2002). They will probably have different-sized satellites, some of them with liquid water, as in the case of Europa.

In the near future, technology will probably lead to the detection of extra-solar, Earth-like planets, some of them perhaps with surface and/or subsurface liquid water in different amounts, as indicated by dynamical simulations (Raymond et al. 2004). Importantly, some of these extrasolar "Earths" may have evolved to real "waterworlds". In the early evolution of the giant planets, resonant interactions with planetesimals during the initial stages of accretion may drive them to migrate to orbits typically four to ten times closer to their central star than Mercury's (Murray et al. 1998). If the migration also occurs in terrestrial planets (1-8 Earth masses) formed in ice-rich, cold regions of the protoplanetary disk, water-ice rich worlds would then come closer to their star, thereby melting substantial amounts of ice and thus creating planetary surfaces entirely blanketed by oceans, up to 25 times deeper than those on Earth (Léger et al. 2004).

\section{Conclusions}

The nascent field of extraterrestrial hydrogeology is rapidly coming into its own. Recent missions to Mars have confirmed the existence of water and related fluvial processes that imply the existence of an Earth-like hy- drological cycle in the geologic past. Present-day Mars still cycles appreciable amounts of water, and beneath its subsurface cryosphere may exist groundwater processes similar to those on to Earth. There is evidence that Venus may have also once had an Earth-like hydrological cycle, causing suppositions that water may still be beneath the surface today, albeit in a supercritical liquid phase. Mercury and the Moon have ice at their poles, most likely accumulated from cometary impacts. In the outer solar system, the Galilean satellites of Jupiter are water abundant, the most intriguing of which, Europa, may possess a vast ocean beneath its icy crust. Saturn's moon, Titan, reveals the intriguing possibility of a hydrological cycle without water, instead involving methane and other hydrocarbons. Neptune's satellite, Triton, may also cycle hydrocarbons, although with less available energy than Titan. Pluto, comets, and other icy bodies are shedding light on the origins of water in the solar system, and recent data on extrasolar planets raise the possibility of other planets similar to Earth, waterworlds covered in immensely deep oceans, or gas giants with inner, hyperpressurized oceans.

The variance of hydrological cycles in the solar system is great, involving variations on the processes familiar to Earth (i.e., Mars), including other chemicals in a pseudohydrological cycle (i.e., Titan), or having water exist in a manner utterly alien to our planet (i.e., Neptune). Many of these variations have been proposed to be conducive to the evolution of life. It is an exciting opportunity for hydrogeology; studying and understanding all the variations possible for a planetary hydrosphere, ultimately improves our own understanding of the water-related processes here on Earth. This is likely to be manifest in all aspects of hydrologic science, ranging from improved measurement methods, to advanced conceptual models of fluid flow under widely varying geologic and atmospheric conditions, to opportunities to test geostatistical concepts applied to hydrogeology.

\section{References}

Abe Y, Matsui T (1988) Evolution of an impact-generated H2O$\mathrm{CO} 2$ atmosphere and formation of a hot proto-ocean on Earth. J Atmos Sci 45(21):3081-3101

Amend JP, Shock EL (1998) Energetics of amino acid synthesis in hydrothermal ecosystems. Science 281:1659-1662

Anderson JD, Schubert G, Jacobson RA, Lau EL, Moore WB, Sjogren WL (1998) Europa's differentiated internal structure: inferences from four Galileo encounters. Science 281:20192022

Anderson JD, Jacobsen RA, McElrath TP, Schubert G, Moore WB, Thomas PC (2001) Shape, mean radius, gravity field, and interior structure of Callisto. Icarus 153:157-161

Baker VR (1982) The channels of Mars, University of Texas Press, Austin

Baker VR (1993) Extraterrestrial geomorphology: Science and philosophy of Earthlike planetary landscapes. Geomorphology 7:9-35

Baker VR (2001) Water and the Martian landscape. Nature 412:228-236

Baker VR, Milton DJ (1974) Erosion by catastrophic floods on Mars and Earth. Icarus 23:27-41 
Baker VR, Partridge JB (1986) Small Martian valleys: pristine and degraded morphology. J Geophys Res 91:3561-3572

Baker VR, Carr MH, Gulick VC, Williams CR, Marley MS (1992a) Channels and valley networks. In: Kieffer HH, Jakosky B, Snyder C (eds) University of Arizona Press, Tucson, pp 493522

Baker VR, Komatsu G, Parker TJ, Gulick VC, Kargel JS, Lweis JS (1992b) Channels and valleys on Venus: preliminary analysis of Magellan data. J Geophys Res 97:13421-13444

Baker VR, Strom RG, Gulick VC, Kargel JS, Komatsu G, Kale VS (1991) Ancient oceans, ice sheets and the hydrological cycle on Mars. Nature 352:589-594

Baker VR, Maruyama S, Dohm JM (2002) A theory of early plate tectonics and subsequent long-term superplume activity on Mars. Electronic Geosciences 7: (http://lin.springer.de/service/ journals/10069/free/conferen/superplu/)

Baumstark-Khan C, Facius R (2002) Life under conditions of ionizing radiation. In: Horneck G, Baumstark-Khan $\mathrm{C}$ (eds) Astrobiology: The quest for the conditions of life. Springer, Berlin Heidelberg New York, pp 261-284

Berman DC, Hartmann WK (2002) Recent fluvial, volcanic, and tectonic activity on the Cerberus plains of Mars. Icarus 159:1-17

Boynton WV, Feldman WC, Squyres SW, Prettyman T, Brückner J, Evans LG, Reedy RC, Starr R, Arnold JR, Drake DM, Englert PAJ, Metzger AE, Mitrofanov I, Trombka JI, d'Uston C, Wänke H, Gasnault O, Hamara DK, Janes DM, Marcialis RL, Maurice S, Mikheeva I, Taylor GJ, Tokar R, Shinohara C (2002) Distribution of hydrogen in the near-surface of Mars: evidence for subsurface ice deposits. Science 297:81-85

Brown RH., Cruikshank DP, Pendleton Y, Veeder GJ (1997) Surface composition of Kuiper Belt object 1993SC. Science 276:937-939

Brown RH, Cruikshank DP, Pendleton Y, Veeder GJ (1998) Identification of water ice on the Centaur 1997 CU26. Science 280:1430-1432

Bullock MA, Grinspoon DH (2001) The recent evolution of climate on Venus. Icarus 150:19-37

Burr DM, McEwen AS, Sakimoto SE (2002) Recent aqueous floods from the Cerberus Fossae, Mars. Geophys Res Lett 29:DOI:10.1029/2001GL013345

Cameron AG, Benz W (1991) The origin of the moon and the single impact hypothesis. Icarus 92:204-216

Carlson RW, Anderson MS, Johnson RE, Smythe WD, Hendrix AR, Barth CA, Sonderblom LA, Hansen GB, McCord TB, Dalton JB, Clark RN, Shirley JH, Ocampo AC, Matson DL (1999) Hydrogen peroxide on the surface of Europa. Science 283:2062-2064

Carr MH (1996) Water on Mars. Oxford University Press, New York

Carr MH et al. (1998) Evidence for a subsurface ocean on Europa. Nature 391:363-365

Cassen PM, Peale SJ, Reynolds RT (1982) Structure and thermal evolution of the Galilean satellites. In: Morrison D (ed) Satellites of Jupiter. University of Arizona Press, Tucson, pp 93-128

Chan MA, Beitler B, Parry WT, Ormö J, Komatsu G (2004) A possible terrestrial analogue for haematite concretions on Mars. Nature 429:731-734

Chanover NJ, Anderson CM, McKay CP, Rannou P, Glenar DA, Hillman JJ, Blass WE (2003) Probing Titan's lower atmosphere with acousto-optic tuning. Icarus 163:150-163

Chaplin MF (2003) Professor at School of Applied Science, London South Bank University, http://www.sbu.ac.uk/water/phase.html, Web site accessed 4 February 2005

Chyba CF (2000) Energy for microbial life on Europa. Nature 403:381-382

Chyba CF, Phillips C (2002) Europa as an abode of life. Orig Life Evol Biosph 32:47-68

Clifford SM (1993) A model for the hydrologic and climate behavior of water on Mars, J. Geophys Res 98:10,973-11,016

Clifford SM, Parker TJ (2001) The evolution of the Martian Hydrosphere: implications for the fate of a primordial ocean and the current state of the northern plains. Icarus 154 (1):40-79
Cochran AL, Levison HF, Stern SA, Duncan MJ (1995) The discovery of half-sized Kuiper Belt objects using the Hubble Space Telescope. Astrophys J 455:342

Cockell CS (1999) Life on Venus. Planet Space Sci 47:1487-1501

Consolmagno GJ, Lewis J (1976) Structural and thermal models of icy Galilean satellites. In: Gehrels T (ed) Jupiter University of Arizona Press, Tucson, pp 1035-1051

Costard F, Forget F, Mangold N, Peulvast JP (2002) Formation of recent Martian debris flows by melting of near-surface ground ice at high obliquity. Science 295:110-113

Cruikshank DP, Roush TL, Owen TC, Geballe TR, de Bergh C, Schmitt B, Brown RH, Bartholomew MJ (1993) Ices on the surface of Triton. Science 261:742-745

Dalton JB (2003) Spectral behavior of hydrated sulfate salts: implications for Europa mission spectrometer design. Astrobiology 3:771-784

Dermott SF, Sagan C (1995) Tidal effects of disconnected hydrocarbon seas on Titan. Nature 374:238-240

Dohm JM, Ferris JC, Baker VR, Anderson RC, Hare TM, Strom RG, Barlow NG, Tanaka KL, Klemaszewski JE, Scott DH (2001a) Ancient drainage basin of the Tharsis region, Mars: Potential source for outflow channel systems and putative oceans or paleolakes. J Geophys Res 106:32,943-32,958

Dohm JM, Tanaka KL, Hare TM (2001b) Geologic map of the Thaumasia region of Mars. USGS Misc Inv Ser Map I-2650, scale 1:5,000,000

Dohm JM, Barlow NG, Williams JP, Baker VR, Anderson RC, Boynton WV, Fairen AG, Hare TM (2004) Ancient giant basin/ aquifer system in the Arabia region, Mars. Lunar Planet Sci Conf, XXXV, \#1209 (abstract) [CD-ROM]

Edgeworth KE (1943) The evolution of our planetary system. J Br Astron Assoc 53:181-188

Edgeworth KE (1949) The origin and evolution of the solar system. Mon Not R Astron Soc 109:600-609

Elliot JL, Hammel HB, Wasserman LH, Franz OG, McDonald SW, Person MJ, Olkin CB, Dunham EW, Spencer JR, Stansberry JA, Buie MW, Pasachoff JM, Babcock BA, McConnochie TH (1998) Global warming on Triton. Nature 393:765-767

Fairén AG, Ruiz J (2003) Seas under ice: stability of liquid-water oceans under icy worlds. Lunar Planet Sci Conf, XXXIV, \#1139 (abstract) [CD-ROM]

Fairén AG, Dohm JM, Baker VR, de Pablo M, Ruiz J, Ferris JC, Anderson RC (2003) Episodic flood inundations of the northern plains of Mars. Icarus 165:53-67

Fairén AG, Fernández-Remolar DC, Dohm JM, Baker VR, Amils R (2004) Inhibition of carbonate synthesis in acidic oceans on early Mars. Nature 431:423-426

Farmer CB, Doms PE (1979) Global and seasonal variation of water vapor on Mars and the implications for permafrost. J Geophys Res 84:2881-2888

Fegley B Jr, Treiman AH (1992) Chemistry of atmospheric-surface interactions on Venus and Mars. In: Luhmann JG, Tatrallyay M, Pepin RO (eds), Venus and Mars: atmospheres, ionospheres and solar wind interactions. Geophys Monogr 66:7-72

Feldman WC, Maurice S, Lawrence DJ, Little RC, Lawson SL, Gasnault O, Wiens RC, Barraclough BL, Elphic RC, Prettyman TH, Steinberg JT, Binder AB (2001) Evidence for water ice near the lunar poles. J Geophys Res 106:23231-23252

Feldman WC, Boynton WV, Tokar RL, Prettyman TH, Gasnault O, Squyres SW, Elphic RC, Lawrence DJ, Lawson SL, Maurice S, McKinney GW, Moore KR, Reedy RC (2002) Global distribution of neutrons from Mars: results from Mars Odyssey. Science 297:75-78

Ferris JC, Dohm JM, Baker VR, Maddock T (2002) Dark slope streaks on Mars: are aqueous processes involved? Geophys Res Lett 29:10.1029/2002GL014936

Ford EB, Seager S, Turner EL (2001) Characterization of extrasolar terrestrial planets from diurnal photometric variability. Nature 412:885-887

Florensky CP, Volkov VP, Nikolaeva OV (1978) A geochemical model of the Venus troposphere. Icarus 33:537-553 
Fortes AD (2000) Exobiological implications of a possible ammonia-water ocean inside Titan. Icarus 146:444-452

Geissler PE, et al. (1998) Evidence for non-synchronous rotation of Europa. Nature 391:368-370

Golombek MP, Bridges NT (2000) Erosion rates on Mars and implications for climate change: constraints from the Pathfinder landing site. J Geophys Res 105:1841-1853

Greeley R, Guest JE (1987) Geologic map of the eastern equatorial region of Mars. USGS Misc Inv Ser Map I-1802B $(1: 15,000,000)$

Greenberg R, Geissler P (2002) Europa's dynamic icy crust, Meteor. Planet Sci 37:1685-1710

Greenberg R, Tufts BR, Geissler P, Hoppa GV (2002) Europa's crust and ocean: how tides create a potentially habitable setting physical setting. In: Horneck G, Baumstark-Khan C (eds) Astrobiology: the quest for the conditions of life. Springer, Berlin Heidelberg New York, pp 111-124

Grinspoon DH (1997) Venus revealed: a new Look below the clouds of our mysterious twin planet. Perseus Publishing, Cambridge, MA, USA

Gulick VC (1998) Magmatic intrusions and hydrothermal origin for fluvial valleys on Mars. J Geophys Res 103:19365-19387

Hartmann WK, Berman DC (2000) Elysium Planitia lava flows: crater count chronology and geological implications. J Geophys Res 105:15, 011-15, 025

Head JW, Pappalardo RT (1999) Brine mobilization during lithospheric heating on Europa: Implications for formation of chaos terrain, lenticula texture, and color variations. J Geophys Res 104: $27,143-27,155$

Head JW, Hiesinger H, Ivanov MA, Kreslavsky MA, Pratt S, Thomson BJ (1999) Possible ancient oceans on Mars: evidence from Mars Orbiter laser altimeter data. Science 286:2134-2137

Head JW, Mustard JF, Kreslavsky MA, Milliken RE, Marchant D (2003) Recent ice ages on Mars. Nature 426:797-802

Hoppa GV, Tufts BR, Greenberg R, Geissler PE (1999) Formation of cycloidal features on Europa. Science 285:1899-1902

Hubbard W (1984) Planetary interiors. Van Nostrand Reinhold, New York

Irion R (2004) The search for pale blue dots. Science 303:30-32

Irwin LN, Schulze-Makuch D (2003) Strategy for modeling putative multilevel ecosystems on Europa. Astrobiology 4:813-821

Irwin M, Tremaine S, Zytkow A (1995) A search for slow moving objects and the luminosity function of the Kuiper Belt. Astrophys J Lett 110:3082-3092

Ivanov MA, Head JW (2001) Geology of Venus: mapping of a global traverse at $30^{\circ} \mathrm{N}$ latitude. J Geophys Res 106: 17,51517,566

Jakosky B (1998) The search for life on other planets. Cambridge University Press, Cambirdge, UK

Jewitt D, Luu J (1993) Discovery of the candidate Kuiper belt object 1992 QB1. Nature 362:730-732

Jones AP, Pickering KT (2003) Evidence for aqueous fluid-sediment transport and erosional processes Venus. J Geol Soc $160: 319-327$

Kargel JS, Strom RG (1992) Ancient glaciation on Mars. Geology 20:3-7

Kargel JS, Lunine JI (1998) Clathrate hydrates on Earth and in the solar system, in Solar system ices. Based on reviews presented at the international symposium "Solar system ices" held in Toulouse, France, on March 27-30, 1995 Publisher: Dordrecht Kluwer Academic Publishers, Astrophysics and space science library (ASSL) Series Vol no. 227. ISBN0792349024., pp 97117

Kargel JS, Baker VR, Beget JE, Lockwood JF, Pewe TL, Shaw JS, Strom RG (1995) Evidence of ancient continental glaciation in the Martian northern plains. J Geophys Res 100:5351-5368

Kargel J, Kaye JZ, Head JW, Marion GM, Sassen R, Crowley JK, Prieto Ballesteros O, Grant SA, Hogenboom DL (2000). Europa's crust and ocean: origin, composition and prospects for life. Icarus 148:226-265

Kasting JF (1988) Runaway and moist greenhouse atmospheres and the evolution of Earth and Venus. Icarus 74:472-494
Kerr RA (2004) Life or volcanic belching on Mars. Science 303:1953

Khare BN, Sagan C, Ogino H, Nagy B, Er C, Schram KH, Arakawa ET (1986) Amino acids derived from Titan tholins. Icarus 68:176-184

Khurana KK, Kivelson MG, Stevenson DJ, Schubert G, Russell CT, Walker RJ, Polanskey C (1998) Induced magnetic fields as evidence for subsurface oceans in Europa and Callisto. Nature 395:777-780

Kivelson MG, Warnecke J, Bennett L, Joy S, Khurana KK, Linker JA, Russell CT, Walker RJ, Polanskey C (1998) Ganymede's magnetosphere: magnetometer overview. J Geophys Res 103: 19,963

Komar PD (1980) Comparisons of the hydraulics of water flows in Martian outflow channels with flows of similar scale on Earth. Icarus 37:156-181

Komatsu G, Baker VR (1997) Paleohydrology and flood geomorphology of Ares Vallis. J Geophys Res 102:4151-4160

Komatsu G, Baker VR, Gulick VC, Parker TJ (1993) Venusian channels and valleys; distribution and volcanological implications. Icarus 102:1-25

Komatsu G, Kargel JS, Baker VR, Strom RG, Ori GG, Mosangini C, Tanaka KL (2000) A chaotic terrain formation hypothesis: explosive outgas and outflow by dissociation of clathrate on Mars. Lunar Planet Sci Conf [CD-ROM], XXXI, abstract 1434

Komatsu G, Gulick VC, Baker VR (2001) Valley networks on Venus. Geomorphology 37:225-240

Komatsu G, Dohm JM, Hare TM (2004) Hydrogeologic processes of large-scale tectono-magmatic complexes in Mongoliasouthern Siberia and on Mars. Geology 32:325-328

Konacki M, Torres G, Jha S, Sasselov DD (2003) An extrasolar planet that transits the disk of its parent star. Nature 421:507509

Krasnopolsky VA (1986) Photochemistry of the atmospheres of Mars and Venus. Springer, Berlin Heidelberg New York, 334 pp

Kreslavsky MA, Head JW (2002) Mars: Nature and evolution of young latitude-dependent water-icerich mantle. Geophys Res Lett 29:DOI:10.1029/2002GL015392

Kuiper GP (1951) In: Hynek JA (ed) Astrophysics: a topical symposium. McGraw-Hill, New York pp 357-424

Léger A, Selsis F, Sotin C, Guillot T, Despois D, Mawet D, Ollivier M, Lebeque A, Valette C, Brachet F, Chazelas B, Lammer H (2004) A new family of planets? "Ocean Planets". Icarus 169:499-504

Levison HF, Morbidelli A, Dones L, Jedicke R, Wiegert PA, Bottke WF Jr (2002) The mass disruption of Oort cloud comets. Science 296:2212-2215

Lissauer JJ (1999) Three planets for Upsilon Andromedae. Nature 398:659-660

Lorenz RD (2002) Thermodynamics of geysers: application to Titan. Icarus 156:176-183

Lorenz RD, Shandera SE (2001) Physical properties of ammoniarich ice: application to Titan. Geophys Res Lett 28:215-218

Lorenz RD, Lunine JI, McKay CP (2000) Geologic settings for aqueous organic synthesis on Titan revisited. Enantiomer 6:8396

Mäkinen JTT, Bertaux J, Combi MR, Quémerais E (2001) Water production of Comet C/1999 S4 (LINEAR) observed with the SQAN instrument. Science 292:1326-1329

Malin MC, Edgett KS (2000a) Sedimentary rocks on early Mars. Science 290:1927-1937

Malin MC, Edget KS (2000b) Evidence for recent groundwater seepage and surface runoff on Mars. Science 288:2273-2412

Marion GM (2001) Carbonate mineral solubility at low temperatures in the Na-K-Mg-Ca-H-Cl-SO $-\mathrm{OH}-\mathrm{HCO}_{3}-\mathrm{CO}_{3}-\mathrm{CO}_{2}-\mathrm{H}_{2} \mathrm{O}$ system. Geochim Cosmochim Acta 65:1883-1896

Marion GM (2002) A molal-based model for strong acid chemistry at low temperatures $(<200$ to $298 \mathrm{~K})$. Geochim Cosmochim Acta 66:2499-2516

Marion GM, Fritsen CH, Eicken H, Payne MC (2003) The search for life on Europa: limiting environmental factors, potential habitats, and earth analogues. Astrobiology 3:785-811 
Matsui T, Tajika E (1991) Early environmental evolution of Venus. Proceedings of the Lunar and Planetary Science Conference, 22:863-864

Max MD, Clifford SM (2001) Initiation of Martian outflow channels: related to the dissociation of gas hydrate? Geophys Res Lett 28:1787-1790

Mayor M, Queloz D (1995) A Jupiter-mass companion to a solartype star. Nature 378:355-359

McCord TB, Hansen GB, Hibbitts CA (2001) Hydrated salt minerals on Ganymede's surface: evidence of an ocean below. Science 292:1523-1525

McKinnon WB (1999) Convective instability in Europa's floating ice shell. Geophys Res Lett 26:951-954

McKinnon WB, Parmentier EM (1986) In: Satellites. University of Arizona Press, Tucson, AZ, pp 718-763

McKinnon WB, Zolensky ME (2003) Sulfate content of Europa's ocean and shell: evolutionary considerations and some geological and astrobiological implications. Astrobiology 4:879898

McKinnon WB, Lunine JI, Banfield D (1995) Origin and evolution of Triton. In: Cruikshank DP (ed) Neptune and Triton. University of Arizona Press, Tucson, pp 807-877

Mellon MT, Jakosky BM (1995) The distribution and behavior of Martian ground ice during past and present epochs. J Geophys Res 100:11781-11799

Miner E, Wessen R (2002) Neptune: The planet, rings, and satellites. Ed. Praxis, Chichester, England

Miyamoto H, Dohm JM, Baker VR, Beyre RA, Bourke M (2004a) Dynamics of unusual debris flows on Martian sand dunes. Geophys Res Lett 31:DOI:10.1029/2004GL020313

Miyamoto H, Dohm JM, Beyer RA, Baker VR (2004b) Fluid dynamical implications of anastomosing slope streaks on Mars. J Geophys Res 109:E06008, DOI:10.1029/2003JE002234

Moore JM (2004) Blueberry fields for ever. Nature 428:711-712

Moore WB, Asphaug E, Sullivan RJ, Klemaszewski JE, Bender KC, Greeley R, Geissler PE, McEwen AS, Turtle EP, Phillips CB, Tufts BR, Head JW, Pappalardo RT, Jones KB, Chapman CR, Belton MJS, Kirk RL, Morrison D (1998a) Large impact features on Europa: Results of the Galileo nominal mission. Icarus 135:127-145

Moore JM, Spencer JR, Asphaug E, Morrison D, Klemaszewski James E, Sullivan Robert J, Chuang Frank C, Greeley Ronald, Bender Kelly C, Geissler Paul E, Chapman Clark R, Pilcher Carl B, the Galileo SSI Team (1998b) Mass movement and landform degradation on Callisto and Ganymede as observed during the Galileo nominal mission: the role of sublimation. Lunar Planet Sci Conf, \#1553

Mouginis-Mark PJ (1985) Volcano/ground ice interactions in Elysium Planitia, Mars. Icarus 64:265-284

Mouginis-Mark PJ (1990) Recent water release in the Tharsis region of Mars. Icarus 84:362-373

Mumma MJ, Dello Russo, DiSanti MA, Magee-Sauer K, Novak RE, Brittain S, Rettig T, McLean IS, Reuter DC, Xu LH (2001) Organic composition of C/1999 S4 (LINEAR): A comet formed near Jupiter? Science 292:1334-1339

Murray N, Hansen B, Holman M, Tremaine S (1998) Migrating planets. Science 279:69-72

Oort JH (1950) The structure of a cloud of comets surrounding the solar system and a hypothesis concerning its structure. Bull Astron Inst Neth 11:91-110

Oró J (1961) Comets and the formation of biochemical compounds on the primitive Earth. Nature 190:389-390

Paige DA (1992) The thermal stability of near-surface ground ice on Mars, Nature 356:43-45

Pappalardo RT, Belton MJS, Breneman HH, Carr MH, Chapman CR, Collins GC, Denk T, Fagents S, Geissler PE, Giese B, Greeley R, Greenberg R, Head JW, Helfenstein P, Hoppa G, Kadel SD, Klassen KP, Klemaszewski JE, Magee K, McEwen AS, Moore JM, Moore WB, Neukum G, Phillips CB, Prockter LM, Schubert G, Senske DA, Sullivan RJ, Tufts BR, Turtle EP, Wagner R, Williams KK (1999) Does Europa have a surface ocean? Evaluation of the geological evidence. J Geophys Res 104:24015-24055

Parker TJ, Gorsline DS, Saunders RS, Pieri DC, Schneeberger DM (1993) Coastal geomorphology of the Martian northern plains. J Geophys Res 98:11,061-11,078

Raymond SN, Quinn T, Lunine JI (2004) Making other earths: dynamical simulations of terrestrial planet formation and water delivery. Icarus 168:1-17

Riley J, Hoppa GV, Greenberg R, Tufts BR, Geissler P (2000) Distribution of chaotic terrain of Europa. J Geophys Res 105: 22,599-22,615

Rodriguez JAP, Sasaki S, Miyamoto H, Dohm JM (2004a) Control of impact crater-related fracture systems on the subsurface hydrology and ground collapse. Lunar Planet Sci Conf, XXXV, \#1676 (abstract) [CD-ROM]

Rodriguez JAP, Sasaki S, Miyamoto H, Dohm JM (2004b) Significance of confined cavernous systems for outflow channel water sources, reactivation mechanisms, and chaos formation. Lunar Planet Sci Conf, XXXV, \#1676 (abstract) [CD-ROM]

Roe HG, de Pater I, Macintosh BA, McKay CP (2002) Titan's clouds from Gemini and Keck adaptive optics imaging. Astrophys J 581(2):1399-1406

Ross RG, Kargel JS (1998) Thermal conductivity of ices with special reference to Martian polar caps. In: Schmitt B, De Bergh C, Festou M (eds) Solar system ices. Kluwer Academic Publishers, Dordrecht, pp 33-62

Ruiz J (2001) Stability against freezing of an internal liquid-water ocean in Callisto. Nature 412:409-411

Ruiz J, Fairén AG (2002) Seas under ice: stability of oceans within icy worlds. 2nd European Workshop on Exo/Astrobiology, Graz, Austria (abstract)

Sagan C, Thompson WR, Khare BN (1992) Titan: a laboratory for prebiological organic chemistry. Acc Chem Res 25:286-292

Sagan C, Khare BN, Thompson WR, McDonald GD, Wing MR, Bada JL, Vo-Dinh T, Arakawa ET (1993) Polycyclic aromatic hydrocarbons in the atmospheres of Titan and Jupiter. Astrophys J 414:399-405

Schenk PM, McKinnon WB, Gwynn D, Moore JM (2001) Flooding of Ganymede's bright terrains by low-viscosity water-ice lavas. Nature 410:57-50

Schulze-Makuch D, Irwin LN (2002a) Reassessing the possibility of life on Venus: proposal for an astrobiology mission. Astrobiology 2:197-202

Schulze-Makuch D Irwin LN (2002b) Energy cycling and hypothetical organisms in Europa's ocean. Astrobiology 2:105-121

Schulze-Makuch D Irwin LN. (2004) Life in the universe: expectations and Constraints. Springer, Berlin Heidelberg New York

Schulze-Makuch D, Abbas O (2004) Titan: a prime example for alternative possibilities of life? In press as book chapter for Exobiology of Titan. Simakov Michael (ed)

Schulze-Makuch D, Grinspoon DH, Abbas O, Irwin LN, Bullock MA (2004) A sulfur-based survival strategy for putative phototrophic life in the Venusian atmosphere. Astrobiology 4:1118

Scott DH, Tanaka KL (1986) Geologic map of the western equatorial region of Mars. USGS Misc Inv Ser Map I-1802-A $(1: 15,000,000)$

Scott DH, Dohm JM, Rice JW Jr (1995) Map of Mars showing channels and possible paleolake basins. USGS Misc Inv Ser Map I-2461 (1:30,000,000)

Showman AP, Malhotra R (1999) The Galilean satellites. Science 286:77-84

Seibert NM, Kargel JS (2001) Small-scale Martian polygonal terrain: Implications for liquid surface water. Geophys Res Lett 28:899-903

Slade MA, Butler BJ, Bryan J, Muhleman DO (1992) Mercury radar imaging- evidence for polar ice. Science 258:635-640

Smith MD (2002) The annual cycle of water vapor on Mars as observed by the thermal emission spectrometer. J Geophys Res 107:DOI 10.1029/2002JE001841

Smith BA, Soderblom LA, Johnson TV, Ingersoll AP, Collins SA, Shoemaker EM, Hunt GE, Masursky H, Carr MH, Davies ME, 
Cook AF, Boyce JM, Danielson GE, Owen TC, Sagan C, Beebe RF, Veverka J, Strom RG, McCauley JF, Morrison D, Briggs GA, Suomi VE (1979) The Jupiter system through the eyes of Voyager 1. Science 204:951-972

Smith BA, 64 colleagues (1989) Voyager 2 at Neptune: imaging science results. Science 246:1.422-1.449

Soderblom LA, Kieffer SW, Becker TL, Brown RH, Cook AF, Hansen CJ, Johnson TV, Kirk RL, Shoemaker EM (1990) Triton's geysers-like plumes: discovery and basic characterization. Science 250:410-415

Spencer JR, Tamppari LK, Martin TZ, Travis LD (1999) Temperatures on Europa from Galileo photopolarimeter-radiometer: nighttime thermal anomalies. Science 284:1514-1516

Squyres SW, Athena Science Team (2004) Initial results from the MER Athena science investigation at Gusev Crater and Meridiani Planum. Lunar Planet Sci Conf, XXXV, \#2187 (abstract) $[\mathrm{CD}-\mathrm{ROM}]$

Stern SA (2003) The evolution of comets in the Oort cloud and Kuiper belt. Nature 424:639-642

Stevenson D (1998) An ocean within Callisto? Eos Trans. AGU Fall Meeting, abstract PB12-10

Tanaka KL (1986) The stratigraphy of Mars. Proceedings of the 17th Lunar Planet Sci Conf, in J. Geophys Res, Part 1, 91:E139-E158

Thomson WR, Sagan C (1990) Color and chemistry on Triton. Science 250:415-418

Throop HB, Bally J, Esposito LW, McCaughrean MJ (2001) Evidence for dust grain growth in young circumstellar disks. Science 292:1686-1689
Tokano T, Neubauer FM, Laube M, McKay CP (2001) Threedimensional modeling of the tropospheric methane cycle on Titan. Icarus 153:130-147

Vinogradov ME, Vereshchaka AL, Shushkina EA (1996) Vertical structure of the zooplankton communities in the oligotrophic areas of the northern Atlantic, and influence of the hydrothermal vent. Okeanologiya 36:71-79

Volkov VP, Zolotov MY, Khodakovsky IL (1986) Lithosphericatmospheric interactions on Venus. In: Saxena SK (ed) Chemistry and physics of the terrestrial planets. Springer, Berlin Heidelberg New York, pp 136 -190

Watts AW, Greeley R, Melosh HJ (1991) The formation of terrains antipodal to major impacts. Icarus 93:159-168

Weissman PR (1996) In: Rettig TW, Hahn JM (eds) Completing the inventory of the solar system. ASP Conf Proc 107:265-288

Williams JP, Paige DA, Manning CE (2003) Layering in the wall rocks of Valles Marineris: intrusive and extrusive magmatism. Geophys Res Lett 30:10.1029/2003GL017662

Williams DA, Klemaszewski JE, Chuang FC, Greeley R (2001) Galileo imaging observations of the Valhalla antipode: Support for a subsurface ocean on Callisto? DPS Meeting, Abstract \#35.06

Zolotov MY, Shock EL (2003) Energy for biologic sulfate reduction in a hydrothermally formed ocean on Europa. J Geophys Res Planets 108: 10.1029/2002JE001966 